\title{
Contaminant Extractability by Electrokinetics
}

\author{
Albert T. Yeung* \\ Department of Civil Engineering \\ The University of Hong Kong \\ Hong Kong
}

\begin{abstract}
Electrokinetic extraction is an emerging technology that has shown considerable potential for efficient and effective removal of both inorganic and organic contaminants from fine-grained soils of low hydraulic conductivity and large specific area when conditions are favorable. The cleanup technology is basically the application of a direct-current electric field across contaminated soils through electrodes installed in the subsurface. The contaminant is removed by (1) electro-osmotic advection of pore fluid flushing the contaminants; (2) ionic migration or electromigration of contaminants carrying charges; and (3) electrophoresis of charged colloidal-sized particles carrying contaminants. However, many complicated electrochemical phenomena that can change the electrokinetic properties of soil particles and the chemistry of pore fluid occur simultaneously. The resulting soil-chemical interactions may enhance or inhibit the extractability of contaminants by electrokinetics, as various electrochemical processes are dynamic, reversible, and interdependent. The impacts of these phenomena on contaminant extractability by electrokinetics are discussed in this paper. A comprehensive list of useful references on electrokinetic extraction is also included for use by readers interested in the subject.
\end{abstract}

Key words: electrokinetics; extractability; electrokinetic extraction; cleanup technology; site remediation; electro-osmosis; electromigration; ionic migration; electrophoresis

\section{INTRODUCTION}

$\mathbf{T}$ HE PRIMARY IDEAL GOAL of site remediation or cleanup is to restore soil and groundwater quality and the associated ecosystems to precontamination or natural conditions. Numerous technologies for site remediation exist. Some technologies have more applications than others, and some are more specialized or contaminant specific. No technology or combination of technologies is suitable for all sites and/or all contaminants, as most technologies are specific to contaminant and/or subsurface conditions. It should also be noted that soil and groundwater quality can rarely, if ever, be restored to precontamination or natural conditions after the subsurface has been contaminated.

Pump-and-treat or soil flushing is one of the most economical remediation technologies for saturated soils if the nature of contaminants and subsurface conditions permit (Mulligan et al., 2001). However, contaminants in fine-grained soils cannot be efficiently or effectively

*Corresponding author: Department of Civil Engineering, The University of Hong Kong, Pokfulam Road, Hong Kong. Phone: 852-28598018; Fax: 852-25595337; E-mail: yeungat@hkucc.hku.hk 
removed by the pump-and-treat technology because of the low hydraulic conductivity and large specific area of the soil. Too low a hydraulic gradient applied to finegrained soils will take too long to complete the cleanup process, as the rate of permeation of flushing fluid through the soil is too low. Too high an applied hydraulic gradient may induce hydraulic fractures in the soil. These fractures may provide preferential paths for the contaminant to spread randomly in the subsurface and aggravate the situation. In hydraulically heterogeneous fine-grained soils, the flushing fluid permeates contaminated soils preferentially through paths of the least hydraulic resistance, rendering zones of low hydraulic conductivity practically untreated during the flushing process. The large specific area of fine-grained soil further complicates the situation by providing numerous active reaction sites for soil-contaminant interactions such as surface complexation and sorption/desorption of contaminants. For example, the timedependent sorption/desorption processes between the contaminant and soil particle surfaces may provide incorrect indication of the degree of cleanup. If the rate of pore fluid replacement is faster than the rate of desorption of contaminant into the pore fluid, the pore fluid will be free of contaminant during fluid replacement. Subsequently, it will be recontaminated by the contaminant desorbed from soil particle surfaces shortly after termination of the fluid replacement process.

Many soil-contaminant interactions will cause contaminants to sorb on soil particle surfaces, rendering them temporarily immobile. If these interactions are permanent and irreversible, they can be used to solidify and stabilize contaminants in situ. Unfortunately, these interactions are dynamic, dependent on environmental conditions such as $\mathrm{pH}$ and temperature, and may be reversible when environmental conditions change. Therefore, they cannot provide reliable long-term containment of contaminants. However, they complicate the difficult task of fine-grained soil remediation being faced by geoenvironmental professionals. The task can be time-consuming and costly even if a technically feasible and legally acceptable solution is identified. The success of any chosen technology or combination of technologies thus depends on numerous environmental factors and operational parameters. Electrokinetic extraction is no exception. The complicated electrochemical processes associated with the remediation technology that affect the extractability of contaminants by electrokinetics are discussed in detail in this paper. A comprehensive list of useful references is also included for interested readers to further their research in the subject.

\section{ELECTROKINETIC PHENOMENA IN FINE-GRAINED SOILS}

Electrokinetic phenomena in fine-grained soils stem from the molecular structure of clay. The surfaces of clay particles are normally negatively charged because of isomorphous substitutions and the presence of broken bonds (Mitchell, 1993; Yeung, 1994). Adsorbed cations are held tightly to clay particle surfaces by strong electrostatic forces to maintain electrical neutrality. Surplus cations and their associated anions exist as salt precipitates. When clay particles come in contact with water, the salt precipitates go into solution. As the adsorbed cations generate a much higher concentration near clay particle surfaces, they are driven by a concentration gradient to diffuse away from clay particle surfaces to homogenize the ion concentration in the pore fluid. The escaping tendency is counteracted by the electrical attraction of the negatively charged clay particle surfaces. A diffuse double layer is thus formed. Governing equations describing the behavior of the diffuse double layer are given by Hunter (1981), Sposito (1984), Yeung (1992, 1994), and Mitchell (1993).

The diffuse double layer provides a mobile layer of cations in the vicinity of soil particle surfaces. However, the electrokinetic behavior and thickness of the layer depends heavily on the pore fluid chemistry (Hunter, 1981; Sposito, 1984; Yeung, 1992; Mitchell, 1993). If the interconnecting soil pores are idealized as a bundle of capillaries, the wall surface of the capillary is negatively charged and the mobile cations form a concentric shell in close proximity of the wall surface within the capillary. The behavior of the shell depends on the electrokinetic properties of clay particle surfaces, pore fluid chemistry, and their interactions.

Several electrokinetic phenomena arise in clay when there are couplings between hydraulic and electrical driving forces and flows. They can be broadly classified into two groups by the driving forces causing the relative movement between different phases. The first group consists of electro-osmosis, electromigration, or ionic migration, and electrophoresis, in which the liquid, dissolved phase, and solid phase move relative to each other under the influence of an externally applied electrical field. The second group consists of streaming potential and migration or sedimentation potential, in which the liquid or solid phases move relative to each other under the influence of hydraulic and gravitational forces, respectively, inducing an electrical potential difference across the medium. The first group of electrokinetic phenomena is of direct relevance to electrokinetic extraction. A brief discussion of these phenomena is given. 


\section{Electro-osmosis}

When a direct-current electric field is imposed on a wet clay, the mobile cation shell is migrated by the electric field and the fluid inside the shell is carried along, resulting in an advective movement of the pore fluid from the anode (positive electrode) towards the cathode (negative electrode), a phenomenon known as electro-osmosis. It should be noted that electro-osmosis is a coupled flow as a hydraulic flow is induced by an electrical driving force (Mitchell, 1993). Examples of different types of coupled flows are given by Mitchell (1993), and Yeung and Mitchell (1993).

Assuming different distributions of ion concentrations in pore fluid and different fluid flow mechanisms, several theories have been advanced to describe the electroosmosis phenomenon and to quantify the fluid volume flow rate through soils induced by a direct-current electric field with varying degrees of success. Historical background, milestone developments, and theoretical models of the phenomenon are given in detail by Yeung (1994).

The most widely accepted model describing electroosmotic fluid flow is the Helmholtz-Smoluchowski theory, that assumes the existence of layers of opposite charges at the solid-liquid interface and the layers of charges are virtually electrical condensers. The electroosmotic fluid flow velocity $v_{\mathrm{eo}}$ is given by

$$
v_{\mathrm{eo}}=\frac{\varepsilon \zeta \Delta E}{\eta \Delta L}
$$

where $\varepsilon$ is the permittivity of pore fluid between the hypothetical plates $(\mathrm{F} / \mathrm{m})=\varepsilon_{r} \times \varepsilon_{0} ; \varepsilon_{r}$ is the relative permittivity (numerically equal to the dielectric constant in the esu system); $\varepsilon_{\mathrm{o}}$ is the permittivity of free space $\left(8.854 \times 10^{-12} \mathrm{~F} / \mathrm{m}\right) ; \zeta$ is the electrokinetic or zeta potential $(\mathrm{V}) ; \eta$ is the viscosity of the pore fluid $\left(\mathrm{Ns} / \mathrm{m}^{2}\right)$; $\Delta E$ is the change in electrical potential (V); and $\Delta L$ is the change in distance $(\mathrm{m})$. Details of the mathematical derivation of the theory are presented in Yeung (1994). Equation (1) gives a quantitative relationship between the electroosmotic fluid flow velocity and fundamental electrokinetic and hydraulic properties of clay particle surfaces and pore fluid.

In practice, the relationship between the electroosmotic fluid volume flow rate $Q\left(\mathrm{~m}^{3} / \mathrm{s}\right)$ and the imposed electrical gradient $i_{e}(\mathrm{~V} / \mathrm{m})$ is given by

$$
Q=k_{e} i_{e} A
$$

where $k_{e}$ is the coefficient of electro-osmotic conductivity $\left(\mathrm{m}^{2} / \mathrm{V}-\mathrm{s}\right) ; i_{e}$ is the $-\Delta E / \Delta L$ is the electrical gradient $(\mathrm{V} / \mathrm{m})$; and $A$ is the gross total cross-sectional area perpendicular to the flow direction $\left(\mathrm{m}^{2}\right)$. The coefficient of electro-osmotic conductivity is a geotechnical engi- neering property of the soil that gives the average linear hydraulic flow velocity through soil under a unit electrical gradient. Available experimental and field data on the coefficient of electro-osmotic conductivity of different types of soils indicate values of the parameter are generally in the narrow range of $1 \times 10^{-9}$ to $10 \times 10^{-9} \mathrm{~m}^{2} / \mathrm{V}$-s and relatively independent of soil type and pore size but sensitive to the electrolyte concentration in the pore fluid (Mitchell, 1991, 1993; Yeung, 1994).

Comparing Equations (1) and (2), the coefficient of electro-osmotic conductivity given by the HelmholtzSmoluchowski model is (Yeung, 1994; Shang, 1997)

$$
k_{e}=\frac{-\varepsilon \zeta n}{\eta}
$$

where $n$ is the porosity of soil. However, it should be noted that the tortuosity of capillaries has not be accounted for by Equation (3).

The efficiency and economics of the use of electro-osmosis in soils depend on the quantity of water transported per unit electrical charge flowed through the soil. Equation (2) gives no prediction for energy consumption of the fluid flow process. If this needed quantity is denoted by $k_{i}\left(\mathrm{~m}^{3} / \mathrm{C}\right)$, the electro-osmotic coefficient of water transport is then

$$
Q=k_{i} I
$$

Unlike $k_{e}, k_{i}$ may vary over several orders of magnitude depending on factors such as soil type, water content, and electrolyte concentration of pore fluid as

$$
k_{i}=\frac{k_{e}}{\sigma}
$$

where $\sigma$ is the bulk electrical conductivity of the soil including the conductance of pore fluid and solid phase $(\mathrm{S} / \mathrm{m})$. The values of $\sigma$ are in the range of 0.004 to 0.3 $\mathrm{S} / \mathrm{m}$ (40 to 3,000 $\mu \mathrm{S} / \mathrm{m}$ ) (Yeung, 1994). The energy consumption per unit volume of water transported is given by

$$
\frac{P}{Q}=\frac{\Delta E}{k_{i}}
$$

where $P$ is the power consumption (J/s) (Yeung, 1994). It can be observed in Equation (6) that the energy consumption per unit volume of water transported is proportional to the electrical potential applied. However, it should also be noted that electro-osmotic fluid volume flow rate is also proportional to the electrical potential applied as depicted in Equation (2). Therefore, the choice of electrical potential applied is a compromise between energy efficiency and available duration for application of an electric field. 


\section{Electromigration or ionic migration}

Electromigration or ionic migration is the advective movement of the charge-carrying dissolved phase relative to that of the liquid phase. Anionic species (negatively charged ions) move towards the anode and cationic species (positively charged ions) move towards the cathode. When the liquid phase is stationary, the velocity of an ion in a unit electric field, that is, one in which the electrical gradient is $1 \mathrm{~V} / \mathrm{m}$, is called its ionic mobility. At infinite dilution, the ionic mobilities of familiar ions are in the range of $1 \times 10^{-8}$ to $10 \times 10^{-8} \mathrm{~m}^{2} / \mathrm{V}$-s (Mitchell, 1991; Yeung, 1994). In dilute solution, the ionic mobility, $u_{i}$, and diffusion coefficient, $D_{i}$, of an ion $i$ are related by the Nernst-Einstein equation (Alberty, 1983),

$$
\frac{D_{i}}{\mathrm{u}_{i}}=\frac{R T}{\left|z_{i}\right| F}
$$

where $D_{i}$ is the diffusion coefficient of ion $i\left(\mathrm{~m}^{2} / \mathrm{s}\right) ; u_{i}$ is the ionic mobility of ion $i\left(\mathrm{~m}^{2} / \mathrm{V}-\mathrm{s}\right) ; R$ is the universal gas constant $(8.3145 \mathrm{~J} / \mathrm{K} / \mathrm{mol}) ; T$ is the temperature $(\mathrm{K})$; $z_{i}$ is the valence of ion $i$; and $F$ is the Faraday constant (96,500 coulombs $\mathrm{C} / \mathrm{mol})$. As the paths for electromigration or ionic migration in soils are much longer and tortuous than in aqueous solutions, the effective ionic mobilities of ions in soils are considerably smaller (Yeung, 1994; Baraud et al., 1997). Assuming the Nernst-Einstein equation holds for the chemical species in the pore fluid of soils (Yeung, 1990), the effective ionic mobility of ion $i$ in soils can then be related to its effective diffusion coefficient by

$$
u_{i}^{*}=\frac{D_{i}^{*}\left|z_{i}\right| F}{R T}
$$

where $u_{i}^{*}$ is the effective ionic mobility of ion $i\left(\mathrm{~m}^{2} /\right.$ $\mathrm{V}-\mathrm{s})$; and $D_{i}^{*}$ is the effective diffusion coefficient $\left(\mathrm{m}^{2} / \mathrm{s}\right)$. Methods of measurement for the effective diffusion coefficient of chemical species in soils are quite well established. The practical range of effective ionic mobility in saturated fine-grained soils calculated using Equation (8) is $3 \times 10^{-9}$ to $1 \times 10^{-8} \mathrm{~m}^{2} / \mathrm{V}$-s (Mitchell, 1991). However, it should be noted that the validity of the modified Nernst-Einstein equation as depicted in Equation (8) has not been proven experimentally. Moreover, there is no established method of measurement for the effective ionic mobility of chemical species in soils.

\section{Electrophoresis}

Electrophoresis is the advective transport of charged fine particles, colloids, or bacteria in suspension under the influence of an imposed direct-current electric field. The fine particles, colloids, or bacteria will migrate to- wards the anode if they carry negative charges, and towards the cathode if they carry positive charges, while the counterions will migrate in the opposite direction. The zeta potential on the surfaces of clay particles or colloids is negative when the clay particles or colloids carry negative charges, and positive when carrying positive charges. In general, the zeta potential of clay particles or colloids is positive at $\mathrm{pH}$ values lower than the point of zero charge (PZC) and negative at $\mathrm{pH}$ values higher than the PZC (Sposito, 1984, 1998). Most bacteria carry positive charges at low $\mathrm{pH}$ and negative charges at neutral and high pH (DeFlaun and Condee, 1997). In summary, clay particles, colloids, and bacteria migrate towards the anode at high $\mathrm{pH}$ and towards the cathode at low $\mathrm{pH}$.

A very short time after the application of a direct-current electric field, the electric force on the charged particles, colloids, or bacteria is balanced by the resultant of hydrodynamic friction force and electrophoretic relaxation force exerting on them. Detailed descriptions of these different forces are given by Yeung (1994). As the forces imposed on the charged particles, colloids, or bacteria are in equilibrium, the particles, colloids, or bacteria move at a constant electrophoretic velocity, $u$, proportional to the magnitude of the applied electric field, that is,

$$
u=u_{E}\left(-\frac{\Delta E}{\Delta L}\right)
$$

where $u$ is the electrophoretic velocity $(\mathrm{m} / \mathrm{s})$; and $u_{E}$ is the electrophoretic mobility $\left(\mathrm{m}^{2} / \mathrm{V}-\mathrm{s}\right)$. Different mathematical deviations of $u_{E}$ in terms of zeta potential of the particle or colloidal surface, $\zeta$, and permittivity, $\varepsilon$, and viscosity, $\eta$, of the fluid on the basis of different assumptions on the nature of the hydrodynamic friction force and the electrophoretic relaxation force acting on the particle or colloid are given by Yeung (1994). In fact, most zeta potential determination methods deduce the zeta potential of fine particles or colloids from measurements of their electrophoretic mobility.

\section{ELECTROKINETIC EXTRACTION}

Electrokinetic extraction is an emerging technology developed to remove inorganic and organic contaminants from fine-grained soils as an electrical gradient is a much more effective force in driving fluid flow through finegrained soils than a hydraulic force (Mitchell, 1993; Yeung, 1994; Iyer, 2001). It involves the application of a direct-current electric field across contaminated soils through electrodes embedded in the subsurface. The contaminant is removed by the combination of (1) electroosmotic advection of the pore fluid flushing the con- 
taminants; (2) ionic migration or electromigration of contaminants carrying charges; and (3) electrophoresis of charged particles and colloids that carry contaminants on their surfaces. These three contaminant removal mechanisms are depicted in Fig. 1. Moreover, these chemical transport mechanisms can be utilized to inject cleansing fluid, enhancement agents such as complexing agents and surfactants, nutrients, and/or bacteria to improve the effectiveness and efficiency of the process (Yeung et al., 1996; Acar et al., 1997; Budhu et al., 1997; Wong et al., 1997; Thevanayagam and Rishindran, 1998; Rabbi et al., 2000; Lee and Lee, 2001; Kim and Han, 2003; Reddy et al. 2003a, 2003b).

By electro-osmotic advection of pore fluid, contaminants existing in the pore fluid are transported towards the cathode. However, experimental results of recent research indicate the direction of electro-osmotic flow is not necessarily from the anode towards the cathode (Hsu, 1997), but is a function of pore fluid chemistry (Eykholt and Daniel, 1994; Yeung and Hsu, 2005). The relationship between electro-osmotic fluid flow direction and pore fluid chemistry is yet to be fully understood. Nonetheless, electro-osmotic advection is the advective movement of contaminants associated with electro-osmotic flow of fluid. The removal mechanism is applicable to all contaminants in the pore fluid. The contaminants can be in a dissolved phase or an immiscible phase, provided they can be flushed by the advective movement of pore fluid (Bruell et al., 1992; Segall and Bruell, 1992).

By electromigration or ionic migration, negatively charged contaminant moves towards the anode and positively charged contaminant moves towards the cathode. The electromigration or ionic migration removal mechanism is primarily applicable to ions. However, it is also applicable to organic contaminants that dissociate, to some extent (Acar et al., 1992; Acar and Alshawabkeh, 1993; Shapiro and Probstein, 1993; Gopinath, 1994).

Colloidal particles may be transported by a combination of electro-osmosis and electrophoresis if the soil is sufficiently open textured (Kuo and Papadopoulos, 1996). As a result, contaminants bound to mobile particulates can be transported. However, colloidal transport is

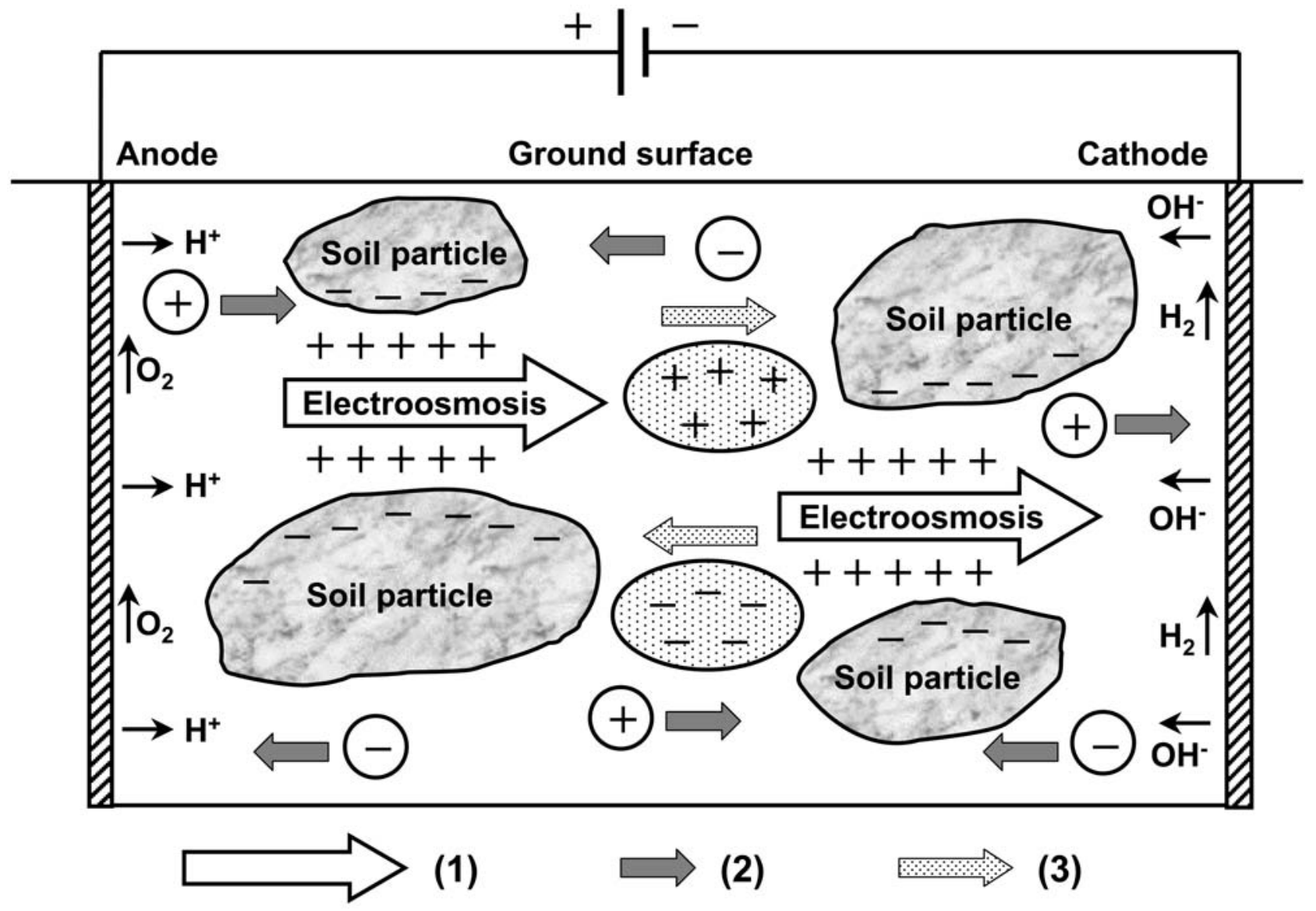

Figure 1. Principle of electrokinetic extraction. 
less important in a natural geologic system as larger colloid-sized particles are typically restrained from migration through the system. Electrophoresis can also transport bacteria to zones of contamination for bioremediation. Results from bench-scale laboratory experiments performed by DeFlaun and Condee (1997) demonstrated that electrophoresis could generate directional bacterial dispersion in situ for bioaugmentation, that is, transport of contaminant-specific competent degradative bacteria away from injection sites and into zones of contamination in the subsurface, as most bacteria carry positive charges at low $\mathrm{pH}$ and negative charges at neutral and high pH (DeFlaun and Condee, 1997).

If electro-osmotic advection flow is from the anode towards the cathode, ionic migration of cations or electrophoresis of fine particles, colloids, or bacteria carrying positive charges is additive to that of electro-osmotic advection. The migration of anions, fine particles, colloids, or bacteria carrying negative charges is the resulting difference of the two removal mechanisms. If reverse electro-osmotic flow occurs, that is, from the cathode towards the anode, the migration of cations and anions are consequently reversed.

Experimental results to date indicate ionic migration is a more effective migration mechanism than electro-osmotic advection. It is evident that the overall phenomenon in cations are driven towards the cathode and anions are driven towards the anode. However, it should be noted that the state of a chemical depends on environmental conditions. For example, metal complexes can exist as anions and/or cations, depending on the $\mathrm{pH}$ of the environment and concentrations of other radicals in the system. As a result, their directions of migration during electrokinetic extraction depend heavily on environmental factors.

After the contaminants have been migrated to the electrodes, they can be removed from the subsurface by electroplating the electrodes, precipitation/coprecipitation in the vicinity of the electrodes, pumping through porous electrodes with an open-flow arrangement, complexation with ion exchange resins, or adsorption onto the electrodes.

Kelsh and Parsons (1997) considered soils responsive to in situ electrokinetic extraction should possess these characteristics: (1) low hydraulic conductivity; (2) presence of water-soluble contaminants (poorly soluble contaminants may require addition of reagents to enhance solubility, for example, carbonate for uranium or surfactants for free phase organic); and (3) relatively low concentrations of ionic materials in the water (they are essential for electro-osmosis and needed to achieve power efficiency for electromigration). On the basis of these identified characteristics, they have tabulated descrip- tions of site geology/hydrology, and types and approximate concentrations of contaminants at 31 U.S. Department of Energy sites with contaminated soils that are likely to be responsive to electrokinetic remediation.

Many complicated phenomena occur simultaneously during the electrokinetic extraction process. These phenomena may include ion diffusion, ion exchange, development of osmotic and $\mathrm{pH}$ gradients, desiccation due to heat generation at the electrodes, mineral decomposition, precipitation of salts or secondary minerals, electrolysis, hydrolysis, oxidation, reduction, physical and chemical adsorption, and fabric changes (Mitchell, 1993). The occurrence of these phenomena can change the chemistry of the soil pore fluid. The resulting soil-chemical interactions may enhance or inhibit extractability of contaminants by electrokinetics.

The technique has also been applied to remove heavy metals from contaminated sludges ex situ (Zagury et al., 1999; Kim et al., 2002b). However, such an application is beyond the scope of this review paper.

\section{RECENT DEVELOPMENTS OF ELECTROKINETIC EXTRACTION}

Early studies on electrokinetic extraction were undertaken to investigate the viability of restoring alkaline and saline soils to arable land. The results of laboratory and field studies of Puri and Anand (1936) indicated that it was possible to leach sodium ions from alkali soils of India by passing a direct electric current through the soil. Similar results were obtained by Gibbs (1966) in largescale model tests. Studies at Moscow University also demonstrated experimentally that the application of a direct electric current during leaching accelerates desalinization of alkaline and saline soils. The measured salt removal rate is proportional to electric current density (Vadyunina, 1968). Results of these early studies signaled the high potential of electrokinetics for contaminant removal from fine-grained soils. Some factors affecting the effectiveness of electrokinetics in contaminant removal were studied by Hamnett (1980), and Agard (1981). Results of their experimental work again demonstrated the possibility of contaminant removal by electrokinetics.

Interest in applying electrokinetics as a soil and groundwater remediation technology rose around the mid-1980s (Lageman, 1993). Researchers in academia and industry have been developing a theoretical understanding of the cleanup process and associated electrokinetic soil-contaminant interactions, performing numerical simulations for these complicated and interacting electrokinetic processes, and carrying out bench-scale 
laboratory and pilot-scale field experiments to establish the viability and practicality of the technology. Many experimental apparatuses and techniques have also been developed (Yeung et al., 1992, 1997c; Yeung, 1994; Page and Page, 2002; Pamukcu et al., 2004). Results of these numerous studies during the last 2 decades indicated the technology was viable but with varying degree of success. However, many complicated phenomena and hurdles for successful implementation of the technology, such as reversal of electro-osmotic flow direction, development of unfavorable $\mathrm{pH}$ environment, etc., have also been identified. New techniques to surmount the hurdles and enhance the technology have thus been developed. Some of these techniques are being commercialized. Detailed reviews of progress in the development of the technology are given by Yeung (1994), Page and Page (2002), and Virkutyte et al. (2002).

\section{EXTRACTABILITY}

Extractability of contaminants from soils depends primarily on the mobility of contaminants within the soil matrix, which is a function of the chemical state of the contaminants, surface characteristics of soil particles, chemistry of pore fluid, and their interactions. Most cleanup technologies utilize advection of pore fluid to migrate contaminants in soil (Mulligan et al., 2001). In addition to electro-osmotic advection, electrokinetic extraction also makes use of the transport mechanisms of advective electromigration and electrophoresis. Therefore, the contaminants must exist as a mobile phase within the soil matrix, such as a dissolved phase in the pore fluid, a colloidal phase suspended in the pore fluid, and/or a mobile immiscible liquid phase coexisting with the pore fluid in soil pores. It is difficult to remove contaminants from a soil that exist as a separate solid phase such as precipitates in soil pores, or as a sorbed phase on soil particle surfaces. Therefore, electrochemical reactions associated with electrokinetic extraction that would affect the mobility of contaminants are of paramount importance on the extractability of contaminants.

\section{FACTORS AFFECTING CONTAMINANT EXTRACTABILITY BY ELECTROKINETICS}

\section{Soil type}

Bench-scale laboratory and pilot-scale field electrokinetic extraction experiments have been performed on many different types of soils including sand (Mohamed, 1996; Li et al., 1997; Chen et al., 1999; Kim and Lee,
1999), silt (Reed et al., 1995; Mohamed, 1996; Yang and Lin, 1998), kaolinites (Hamed, 1990; Hamed et al., 1991; Acar et al., 1994; Gopinath, 1994; Scott, 1994; Acar and Alshawabkeh, 1996; Yeung et al., 1996; Coletta et al., 1997; Dzenitis, 1997; Hsu, 1997; Reddy et al., 1997; Li and Li, 2000; Azzam and Oey, 2001; Kim et al., 2001, 2003; Yeung and Hsu, 2005), illite ( $\mathrm{Li}$ and $\mathrm{Li}, 2000$ ), montmorillonite (Reddy et al., 1997), bentonite (Laursen, 1997; Paillat et al., 2000), natural soils (Grundl and Reese, 1997; Reddy et al., 1997; Reddy and Saichek, 2003), tailing soils (Kim et al., 2002a), and various artificial mixtures of soils (Puppala et al., 1997; Chen et al., 1999; Li and $\mathrm{Li}, 2000$ ).

It can be observed from the results of these experiments that soil type does not pose any significant limitations on the technology. However, contaminant transport rates and efficiencies depend heavily on soil type and environmental variables. Soils of high water content, high degree of saturation, and low activity provide the most favorable conditions for contaminant transport by electro-osmotic advection and ionic migration. Soils of high activity exhibit a high acid/base buffer capacity and are able to maintain a positive electro-osmotic fluid flow, that is, from the anode towards the cathode. However, they may require excessive acid and/or enhancement agents to desorb and solubilize contaminants sorbed on soil particle surfaces before they can be migrated through the subsurface and removed (Yeung et al., 1996, 1997b; Puppala et al., 1997).

The effects of soil mineralogy on the removal of chromium; copper, zinc, and lead; and phenanthrene from soils by electrokinetics were also investigated by Reddy et al. (1997); Darmawan and Wada (2002), and Reddy and Saichek (2003), respectively. Their results indicated the presence of carbonate, hematite, humic-allophanic, and allophanic soils of high buffer capacities could adversely impact the process. Soil type can also affect the sorption-desorption characteristics of hydrophobic organic compounds significantly, but the mechanisms are not fully understood (Hwang et al., 2003). Moreover, the electrokinetic properties of soil particle surfaces can be modified through soil-contaminant interactions (Lorenz, 1969; Hunter and James, 1992; McBride, 1994).

The technology can be applied to effectively treat hydraulically heterogeneous soil deposits. Values of hydraulic conductivity in different types of soils within a heterogeneous deposit can vary by many orders of magnitude. However, their values of coefficient of electroosmotic conductivity are within a much narrower range (Mitchell, 1993; Yeung, 1994). Therefore, the electro-osmotic fluid volume flow rates in different soils will be similar when an electric potential is externally applied across the deposit, as indicated by Equation (2). The rate 
of electromigration or ionic migration is primarily a function of the magnitude of the applied electric field. As a result, similar electroosmotic advection rates of contaminant transport can be induced in different soils within a heterogeneous deposit, resulting in a more uniform cleanup. However, it should be noted that the energy consumption in different soils is proportional to their electrical conductivities. The ability to remove contaminants uniformly from a heterogeneous natural deposit is another distinct advantage of the technology.

\section{Contaminant type and concentration}

Available experimental data indicate the removal of heavy metals such as lead (Hamed et al., 1991; Reed et al., 1995; Rødsand et al., 1995; Acar and Alshawabkeh, 1996; Coletta et al., 1997; Alshawabkeh et al., 1997; Sah and Chen, 1998; Chung and Kang, 1999; Lee and Yang, 2000; Li and Li, 2000; Azzam and Oey, 2001; Kim et al., 2001; Ottosen et al., 2001; Vengris et al., 2001; Darmawan and Wada, 2002; Suèr and Allard, 2003), cadmium (Acar et al., 1994; Reddy and Parupudi, 1997; Sah and Chen, 1998; Reddy and Chinthamreddy, 1999; Kim et al., 2001; Reddy et al., 2001; Vengris et al., 2001; Kim et al., 2003; O'Connor et al., 2003), copper (Runnells and Larson, 1986; Eykholt, 1992; Alshawabkeh et al., 1997; Hansen et al., 1997; Ottosen et al., 1997, 2000, 2001; Maini et al., 2000a, 2000b; Darmawan and Wada, 2002; Velizarova et al., 2002; O'Connor et al., 2003; Sawada et al., 2003), chromium (Haran et al., 1996; Alshawabkeh et al., 1997; Reddy and Parupudi, 1997; Hansen et al., 1997; Chinthamreddy and Reddy, 1999; Reddy and Chinthamreddy, 1999; Reddy et al., 2001; Weng and Yuan, 2001; Velizarova et al., 2002; Reddy and Chinthamreddy, 2003a; Sanjay et al., 2003; Pamukcu et al., 2004), mercury (Cox et al., 1996; Hansen et al., 1997; Reddy et al., 2003a; Suèr and Allard, 2003; Suèr and Lifbergren, 2003), nickel (Reddy and Parupudi, 1997; Reddy and Chinthamreddy, 1999; Reddy et al., 2001), iron (Alshawabkeh et al., 1997), arsenic (Maini et al., 2000b; Velizarova et al., 2002; O'Connor et al., 2003), manganese (Maini et al., 2000b), and zinc (Hicks and Tondorf, 1994; Alshawabkeh et al., 1997; Hansen et al., 1997; Maini et al., 2000b; Ottosen et al., 2001; Vengris et al., 2001; Darmawan and Wada, 2002); radionuclides (Kharkats, 1998; Prozorov et al., 2000); and organics such as phenol (Acar et al., 1992; Gopinath, 1994; Yang and Long, 1999), acetic acid (Gopinath, 1994), TCE (Bruell et al., 1992; Yang and Liu, 2001; Rabbi et al., 2000), PAHs (Maini et al., 2000b), phenanthrene (Ko et al., 2000; Li et al., 2000), polychlorinated dibenzofurans (Suèr and Allard, 2003), BTEX (Bruell et al., 1992; Maini et al., 2000b), motor oil (Paillat et al., 2000), 2,4dichlorephenoxyacetic acid (Jackman et al., 2001), and a proprietary water-soluble solvent (Schultz, 1997) by electrokinetics are feasible. However, enhancement agents may be required in some situations. Removal of freephase nonpolar organics may also be possible if they exist as small bubbles that can be carried by electro-osmotic advection (Mitchell, 1991). Contaminants bound to colloids may also be removed by the combined effects of electro-osmotic advection and electrophoresis (Kuo and Papadopoulos, 1996). In fact, the technology can take advantage of colloid-facilitated transport of contaminants in soils of open texture and is not selective towards the types of contaminant to be removed. Therefore, the type of contaminant does not pose a significant limitation on the technology provided the contaminant does not exist in a sorbed phase on soil particle surfaces or as precipitates in soil pores.

Existing experimental data also indicate the removal of contaminants of high concentrations is possible. However, a high concentration of ions in the pore fluid increases the electrical conductivity of the soil and reduces the efficiency of the electro-osmotic fluid flow as depicted in Equation (5). Moreover, the strength of the applied electric field may have to be reduced to prevent excessive power consumption and heat generation during the process. Nonetheless, the contaminant concentration does not pose any insurmountable hurdle to the application of the process (Alshawabkeh et al., 1999).

\section{Soil $p H$}

During the electrokinetic extraction process, electrolytic decomposition of water occurs at electrodes when a direct-current electric field is imposed on a soil-fluid-chemical system. Hydrogen ions and hydroxide ions are generated at the anode and the cathode, respectively,

$$
\begin{gathered}
2 \mathrm{H}_{2} \mathrm{O}-4 \mathrm{e}^{-} \rightarrow \mathrm{O}_{2} \uparrow+4 \mathrm{H}^{+} \quad \text { (at the anode) } \\
4 \mathrm{H}_{2} \mathrm{O}+4 \mathrm{e}^{-} \rightarrow 2 \mathrm{H}_{2} \uparrow+4 \mathrm{OH}^{-} \text {(at the cathode) }
\end{gathered}
$$

The hydrogen and hydroxide ions are transported into the soil by the applied direct-current electric field resulting in the development of a low $\mathrm{pH}$ environment in the vicinity of the anode and a high $\mathrm{pH}$ environment in the vicinity of the cathode.

An acidic environment promotes desorption of heavy metals from clay particle surfaces and their solubilization in the pore fluid, and protonation of organic functional groups. Conversely, an alkaline environment promotes precipitation of heavy metals by forming metallic hydroxides, rendering the contaminant immobile.

Moreover, the surface electrical potential of soil particles is a function of $\mathrm{pH}$ (Lorenz, 1969; Sposito, 1984, 1998; McBride, 1994). Therefore, the $\mathrm{pH}$ of the envi- 
ronment has a profound impact on the surface charge of soil particles, in particular variable-charge soils (Sposito, 1984). Low $\mathrm{pH}$ conditions occur in soils of low acid/base buffer capacity as a result of the advance of the acid front. The low pH soil conditions impede electro-osmosis and, hence, contaminant removal efficiency. When the $\mathrm{pH}$ of the environment is lower than the point of zero charge (PZC), the polarity of the zeta potential of the soil particle surface is reversed, resulting in a reversal of the electro-osmotic fluid flow direction.

To achieve efficient extraction of contaminants by electrokinetics, it is necessary to maintain a $\mathrm{pH}$ sufficiently low to keep metal contaminants in a mobile phase and a $\mathrm{pH}$ sufficiently high to maintain a negative zeta potential so as to maintain a positive electro-osmotic fluid flow, that is, from the anode towards the cathode (Yeung et al., 1997b). Although the concept appears to be straightforward, simultaneously maintenance of a negative zeta potential on soil particle surfaces and keeping of contaminants in a solubilized phase remains a major obstacle in successful field implementation of electrokinetic extraction as the range of operational $\mathrm{pH}$ may be very narrow or not even exist.

Experimental results of Ko et al. (2000) on removal of phenanthrene from kaolinite by electrokinetic extraction using hydroxypropyl- $\beta$-cyclodextrin as a hydrophobic organic contaminants solubility-enhancing agent indicated the removal efficiency was highly $\mathrm{pH}$-dependent. Without $\mathrm{pH}$ control, the electro-osmotic flow rate was very low after 3 days. The best overall phenanthrene removal was obtained by flushing the anode reservoir with a high hydroxypropyl- $\beta$-cyclodextrin concentration prepared in a $\mathrm{Na}_{2} \mathrm{CO}_{3}$ buffer solution, so that $\mathrm{pH}$ values throughout the specimen were kept at higher than 7.

As $\mathrm{pH}$ has a profound influence on the sorption/desorption characteristics of metals onto/from soil particle surfaces (Yong et al., 1990; Yong and Phadungchewit, 1993; Elzahabi and Yong, 2001), precipitation/dissolution of metals in the pore fluid, and the efficiency of electro-osmotic fluid flow, different techniques have been developed to control the soil $\mathrm{pH}$ during electrokinetic extraction. These techniques involve keeping the $\mathrm{pH}$ at the anode from lowering so as to maintain the electroosmotic fluid volume flow rate, and keeping the $\mathrm{pH}$ at the cathode from rising so as to prevent metal precipitation. The techniques include: (1) use of acetic acid to depolarize the cathode reaction (Rødsand et al., 1995), (2) use of sodium hydroxide to neutralize the anode reaction (Saichek and Reddy, 2003), (3) use of an ion-selective membrane to prevent hydroxide ion migration into the soil from the cathode (Rødsand et al., 1995; Li et al., 1998), (4) rinsing away the hydroxide ions generated at the cathode (Hicks and Tondorf, 1994), (5) use of buffer solutions in the reservoirs and an appropriate electrode configuration (Ko et al., 2000; Yeung and Hsu, 2005), (6) circulation of electrolyte solution from the cathode reservoir to the anode reservoir (Lee and Yang, 2000), and (7) use of special electrodes to control the electroosmotic fluid flow direction (Leinz et al., 1998b; Mattson et al., 2000). These enhancement techniques will be discussed in detail in a later section.

\section{Acid/base buffer capacity of soil}

An acidic or low $\mathrm{pH}$ environment promotes the desorption of heavy metals from soil particle surfaces and solubilization of metal ions in the pore fluid. Ions in the dissolved phase can be removed effectively by electrokinetics. At a higher $\mathrm{pH}$, soil particles sorb more metal contaminants than at a lower $\mathrm{pH}$. Moreover, a high $\mathrm{pH}$ environment also promotes metal precipitation. Both mechanisms immobilize metal contaminants, rendering cleanup more difficult and electrokinetic extraction inefficient. Although a direct-current electric field can generate hydrogen ions at the anode and lower the $\mathrm{pH}$ in the vicinity, the influence of these hydrogen ions on the $\mathrm{pH}$ of the soil being remedied depends heavily on the acid/base buffer capacity of the soil.

Buffer capacity or buffer intensity of a system is defined as the amount of strong base (strong acid) that, when added to the system, causes a unit increase (decrease) in pH. Experimental procedures to measure the buffer capacity of soil specimens have been proposed by Curtin et al. (1996) and Yeung et al. (1996). However, it should be noted that the acid/base buffer capacity of a soil specimen depends on many variables such as soil concentration, ionic strength of the solution, presence of exchangeable cations, method of measurement, etc. Therefore, any reported buffer capacities of soils are applicable only under the given experimental conditions and should not be generalized. Moreover, most natural soils contain impurities such as iron oxides, quartz, titanium oxides, etc., that increase their acid/base buffer capacity and affinity for heavy metals (Ulrich and Sumner, 1991).

Curtin et al., (1996) proposed an equation to predict soil acidity as a function of organic content, amount of soil, and pH. Experimental results by Yeung et al. (1996) indicated the buffer capacity of some natural soils could be adequately high to resist any $\mathrm{pH}$ changes induced by electrolytic decomposition of water during electrokinetic extraction, thus diminishing the advantages of any development of a $\mathrm{pH}$ gradient.

\section{Zeta potential of soil}

Values of zeta potential in most clays are generally in the range of 0 to $-50 \mathrm{mV}$ with a positive charge on the 
mobile ions (Mitchell, 1993; Yeung, 1994). Therefore, electro-osmotic fluid flow will be in the direction of decreasing electrical potential or that of the imposed electric field (i.e., from the anode towards the cathode). However, the polarity of zeta potential depends on the PZC, that is, the $\mathrm{pH}$ at which the net charge on the soil particle surface is zero (Hunter, 1981; Sposito, 1984, 1998).

When the $\mathrm{pH}$ of an environment is higher than the PZC, the soil has a negative zeta potential and electro-osmotic fluid flow is from the anode towards the cathode. Increased acidity causes the zeta potential to become less negative (Lorenz, 1969; Hunter and James, 1992), whereby electro-osmotic fluid flow rates have been observed to decrease with increasing soil acidity (Shapiro and Probstein, 1993; Hamed and Bhadra, 1997; Yeung and $\mathrm{Hsu}, 2005)$. When the $\mathrm{pH}$ of the environment is lower than the PZC, the zeta potential polarity of soil particle surfaces is reversed, resulting in a reversal of electro-osmotic fluid flow direction (Eykholt, 1992; Shapiro and Probstein, 1993; Eykholt and Daniel, 1994; West and Stewart, 1995; Yeung and Hsu, 2005).

Experimental results indicate $\mathrm{pH}$ strongly alters the zeta potential of Georgia kaolinite (Vane and Zang, 1997). However, it does not significantly change that of Wyoming bentonite (Chung, 1995; Vane and Zang, 1997; Yeung et al., 1997a). This is probably due to the constant potential rather than constant charge behavior of bentonite particle surfaces. The results are in agreement with those reported by Miller and Low (1990) on zeta potential measurements of montmorillonite. The zeta potential also tends to become more positive with an increase in the ionic strength of the pore fluid (Hunter, 1981; Yeung et al., 1997a). However, experimental results of Vane and Zang (1997) indicated such effects on kaolinite and bentonite were weak. The effect of ion type is much more pronounced where increasing concentrations of hydrolyzable metal cations, such as $\mathrm{Co}^{2+}, \mathrm{Cd}^{2+}$, $\mathrm{Cu}^{2+}$, etc., can cause the zeta potential to become more positive (Hunter and James, 1992). A reverse electro-osmotic fluid flow (i.e., from the cathode towards the anode) can occur when the concentration of such ions is sufficiently high (Ray and Ramsey, 1987). Moreover, it has been experimentally found that methanol concentration in the pore fluid has a profound impact on the zeta potential of bentonite (Chung, 1995; Yeung et al., 1997a).

\section{Electro-osmotic fluid flow direction}

It can be observed from Equation (1) that the electroosmotic fluid flow velocity is proportional to the applied electrical gradient, $i_{e}$, that is, $\Delta E / \Delta L$, zeta potential, $\zeta$, and pore fluid permittivity, $\varepsilon$, and inversely proportional to the pore fluid viscosity, $\eta$. The electro-osmotic fluid flow direction depends on the zeta potential polarity. If the zeta potential is negative, the fluid flow will be from the anode towards the cathode. If the zeta potential is positive, the fluid flow will be from the cathode towards the anode.

The direction of electro-osmotic fluid flow has a prominent impact on contaminant extractability using electrokinetic extraction. Yeung and Hsu (2005) concluded from their experimental results that an appropriate concentration of EDTA added to the cathode reservoir, combined with a reverse electro-osmotic fluid flow, can be very effective for solubilizing Cd(II) sorbed on Milwhite kaolinite particle surfaces.

Anderson and Idol (1985) analyzed the electro-osmotic phenomenon in a charged capillary of nonuniform electric charge density and modified the Helmholtz-Smoluchowski model. The modified model replaces the constant zeta potential and electric field in Equation (1) with the average product of zeta potential and electric field over the entire specimen. The model is mathematically described as

$$
v_{\mathrm{eo}}=-\frac{\varepsilon<\zeta i_{e}>}{\eta}
$$

where

$$
<\zeta i_{\mathrm{e}}>=\frac{1}{L} \int_{0}^{L}\left(\zeta i_{e}\right)_{x} d x
$$

$v_{\mathrm{eo}}$ is the electro-osmotic fluid flow velocity $(\mathrm{m} / \mathrm{s}) ; \varepsilon$ is the permittivity of the fluid $\left(\mathrm{C}^{2} / \mathrm{N}-\mathrm{m}^{2}\right) ; \eta$ is the viscosity of the fluid $\left(\mathrm{N}-\mathrm{s} / \mathrm{m}^{2}\right)$; $L$ is the total length of the capillary $(\mathrm{m}) ; x$ is a location in the capillary $(\mathrm{m}) ;\left(\zeta i_{e}\right)_{x}$ is the product of $\zeta i_{e}$ at any location, $x$, in the capillary $\left(\mathrm{V}^{2} / \mathrm{m}\right)$; $\left\langle\zeta i_{e}\right\rangle$ is the average value of $\left(\zeta i_{e}\right)_{x}$ over the entire length of the capillary $\left(\mathrm{V}^{2} / \mathrm{m}\right) ; \zeta$ is the zeta potential of soil particle surfaces at location $x(\mathrm{~V})$; and $i_{e}$ is the electric field strength at location $x(\mathrm{~V} / \mathrm{m})$.

Eykholt (1992), and Eykholt and Daniel (1994) were able to predict the magnitude and direction of electro-osmotic fluid flow with the modified Helmholtz-Smoluchowski model using the $\mathrm{pH}$-zeta potential relationship determined by Lorenz (1969). The effects of the presence of contaminant in the pore fluid on zeta potential were not considered. However, it has also been reported by other researchers that the modified Helmholtz-Smoluchowski model fails to predict the direction of electroosmotic fluid flow (Hsu 1997). Therefore, the relationship between zeta potential and electro-osmotic fluid flow direction has yet to be investigated.

\section{Sorption/desorption characteristics of soil particle surfaces}

In general, sorption refers to the transfer of ions from the liquid phase to the solid phase in the soil matrix. It 
can occur via cation exchange on clays and humus, and can also take place by specific adsorption (McBride, 1994) including: (1) cation complexation with organic functional groups and bonding on variable-charge minerals; and (2) anion selective bonding (chemisorption) at variable-charge mineral surfaces and layer silicate particle edges. Specific adsorption is more selective and less reversible, rendering contaminants immobile under certain environmental conditions.

The sorption/desorption characteristics of the soil particle surface are chemical-specific, dynamic, $\mathrm{pH}$-dependent, and reversible. Moreover, the characteristics can be modified by the addition of an enhancement agent (Yeung et al., 1996; Yeung and Hsu, 2005). Heavy metal sorption mechanisms in soils varies with soil $\mathrm{pH}$, and the soil's ability to retain sorbed heavy metals depends on its resistance to any change in soil $\mathrm{pH}$. The sorption of heavy metals increases with increasing $\mathrm{pH}$ and decreases with decreasing $\mathrm{pH}$. Experimental results from column leaching tests of Elzahabi and Yong (2001) indicated the sorption characteristics of heavy metals in unsaturated clay barriers were controlled by many factors that should be taken into consideration including the volumetric water content, wetting time, soil $\mathrm{pH}$, and influent heavy metal concentrations. Simplification of $K_{d}$ as a constant and variation of the degree of saturation as a linear function cannot be considered as valid assumptions and may lead to improper evaluation of the sorption phenomena and serious errors in predicting contaminant transport through soils.

\section{Operational parameters}

Electrode material and shape. Chemically inert and electrically conducting materials such as graphite, coated titanium, or platinum can be used as an anode to prevent electrode dissolution and the generation of undesirable corrosion products in an acidic environment. If necessary, sacrificial electrodes can also be used as the anode. Any conductive materials that do not corrode in a basic environment can be used as the cathode. Important considerations for the choice of electrode material are: (1) electrical conduction properties of the material; (2) availability of the material; (3) ease of fabrication to the form required for the process; (4) ease of installation in the field; and (5) material, fabrication, and installation costs. Regardless of the material selected for the electrode, the electrode has to be installed properly in the field so it makes effective electrical contact with the subsurface. Moreover, the design must make provisions to facilitate exchange of solution with the subsurface through the electrode.

An open electrode configuration allowing exchange of solution between the electrode and the subsurface envi- ronment is essential for proper functioning of the process. Hollow electrodes can facilitate removal of contaminated solution from the subsurface and/or injection of purging solution into the subsurface. The electrodes can be installed horizontally or vertically (Chen and Murdoch, 1997; Murdoch and Chen, 1997). Special electrodes have been developed to control flows of specific ions in and out of the electrodes (Leinz et al., 1998a, 1998b; Mattson et al., 2000).

Electrode configuration. Limited research has been conducted to study the effect of electrode configuration on the efficiency of electrokinetic extraction. Most bench-scale and large-scale laboratory and pilot-scale field studies on electrokinetic remediation performed to date have been one dimensional. Effective and efficient full-scale field application will require an optimal electrode configuration. One-dimensional (1D), two-dimensional (2D), or axisymmetrical electrode configurations may be adopted.

Sheet electrodes can be installed in the field by a procedure similar to the installation of prefabricated vertical drains to provide a $1 \mathrm{D}$ electrode configuration. Use of electrode trenches is a further 1D application. An approximately $1 \mathrm{D}$ electric field can also be obtained by lines of rod electrodes placed in boreholes at close spacing. This is likely to be the easiest method of installation and the most cost-effective approach for in situ remediation. However, this configuration may develop spots of inactive (dead) electric field between electrodes of the same polarity. Hexagonal, square, or triangular electrode configurations can be used for 2D field implementation. In these configurations, the cathode is placed at the center and the anodes are placed on the perimeter to maximize the spread of the acidic environment generated by the anodes and to minimize the extent of the basic environment generated by the cathode (Alshawabkeh et al., 1999). These configurations of electrodes generate 2D nonlinear electric fields. Spots of inactive electric field can still develop in these configurations. However, the areas of these inactive spots are smaller than those developed in the approximate 1D configuration containing parallel lines of anodes and cathodes.

In a 1D configuration, the electric current density, that is, magnitude of electric current per unit area, is independent of location. In 2D configurations, the electric current density increases linearly with distance towards the cathode. Therefore, the electric field strength also increases linearly with distance towards the cathode. The effect of current density on electrokinetic extraction was studied by Hamed and Bhadra (1997) and Pomès et al. (2002). Their experimental results indicated electro-osmotic fluid volume flow rate increased with current den- 
sity, resulting in a considerable reduction in processing time. Moreover, increasing the current density did not result in a considerable increase of energy expenditure per unit volume of processed soil.

Factors affecting the selection of electrode configuration for full-scale field implementation include: (1) locations and size of any inactive electric field spots that may develop; (2) number and costs of electrodes per unit area to be treated; and (3) time requirements of the designed remediation process. Factors affecting the selection of electrode spacing include: (1) costs; and (2) processing time required. Detailed analyses of these factors are given by Schultz (1997) and Alshawabkeh et al. (1999).

\section{Enhancement techniques}

Effects of both $\mathrm{H}^{+}$and $\mathrm{OH}^{-}$ions on remediation can be problematic for the following reasons: (1) $\mathrm{OH}^{-}$may react with the target cations to form precipitates, rendering them immobile; (2) $\mathrm{H}^{+}$ions may react with soil constituents, mobilizing originally immobile nontarget cations; (3) electro-osmosis decreases with increasing acidity and ion concentration in the pore fluid; therefore, introduction of $\mathrm{H}^{+}$and $\mathrm{OH}^{-}$ions may reduce the efficiency of electro-osmotic fluid transport and thus target contaminants; and (4) transport of $\mathrm{H}^{+}$and $\mathrm{OH}^{-}$consumes a disproportionate amount of the electric current intended for the transport of hazardous ions because of their considerably greater ionic mobilities (Alberty, 1983). Most enhancement techniques are developed to control soil $\mathrm{pH}$ and to keep the contaminants in a mobile state. Moreover, other enhancement techniques are developed to improve the efficiency and effectiveness of electrokinetic extraction by combining the technique with other remediation technologies. Some of these pertinent enhancement techniques are detailed as follows.

Enhancement agents. Contaminants can exist in different chemical states in the subsurface depending on environmental conditions and types of coexisting species (Suèr and Allard, 2003; Suèr et al., 2003). However, only mobile phases are removable by electrokinetic extraction and many other remediation technologies. Transformation processes of the contaminant between different chemical states are contaminant-specific, reversible, and dependent on environmental conditions. Nonetheless, most contaminants can be transformed to their mobile phases.

In many cases, contaminant- and site-specific enhancement agents may be needed to control soil chemistry, and promote solubilization and transport of the contaminant species. In general, enhancement agents should have these important characteristics: (1) they should not form insoluble salts with the contaminant within the range of variation of $\mathrm{pH}$ values during the process; (2) they should form soluble complexes with the contaminant that can be efficiently migrated by a direct-current electric field; (3) they and their contaminant complexes should be chemically stable over a wide range of $\mathrm{pH}$ values; (4) they should have a higher affinity for the contaminant than the soil particle surface; (5) they and their contaminant complexes should not have a strong affinity for the soil particle surface; (6) they should not generate toxic residues in the treated soil; (7) they should not generate an excessive quantity of wastewater, and the end products of the treatment process should be amenable to concentration and precipitation; (8) they should be costeffective including reagent costs, handling costs, and treatment costs for the resulting waste collected and/or wastewater generated; (9) they should not induce excessive solubilization of soil minerals or increase the concentrations of any harmful species in the soil pore fluid; and (10) if possible, they should selectively complex with the target contaminant species.

The use of purging solutions (synthetic or natural), chelating agents, and complexing agents, such as sulfuric acid, citric acid, EDTA, iodine/iodide lixiviant, humic acid, sodium acetate solution, nitric acid, etc., have been demonstrated to be feasible for the extraction of different types of metal contaminants from fine-grained soils (Pamukcu and Wittle, 1992; Eykholt and Daniel, 1994; Cox et al., 1996; Mohamed, 1996; Yeung et al., 1996; Coletta et al., 1997; Hsu, 1997; Wong et al., 1997; $\mathrm{Li}$ and Li, 2000; Kim et al., 2001, 2002a; Suèr and Allard, 2003; Suèr and Lifbergen, 2003; Sawada et al., 2003; Reddy et al., 2003a; Yeung and Hsu, 2005). The enhancement agents are injected into the soil to compete with the soil particle surface to form soluble complexes with metal contaminants. The soluble complexes in the pore fluid are transported by electro-osmotic advection and electromigration towards the electrodes where they are collected and removed. In some other applications, the enhancement agent is simply used to increase the solubility of the contaminant by complex formation. Nonetheless, the choice of enhancement agent is site- and contaminant-specific. In some of these studies, reverse electro-osmotic flows were observed in the soils being treated. Depending on the chemical state of the contaminant, a reverse electroosmotic flow may be beneficial (Hsu, 1997; Yeung and Hsu, 2005).

The sorption characteristics of the metal contaminant on the soil particle surface in the presence of the enhancement agent as a function of $\mathrm{pH}$ must be carefully studied if the primary function of the enhancement agent is to desorb the contaminant from the soil particle surface. It is possible that the enhancement agent can completely change the sorption characteristics of the conta- 
minant. For example, results obtained by Yeung et al. (1996), and Yeung and Hsu (2005) indicated the addition of EDTA promoted sorption of lead and cadmium onto kaolinite particle surfaces in an acidic environment, rendering these metal contaminants immobile. The ability of the enhancement agent to form complexes with the metal contaminant may also be $\mathrm{pH}$ dependent. Although the formation of complexes in free solution can be predicted by solving simultaneous chemical equilibrium equations using appropriate equilibrium constants, the behavior of these complexes in the presence of soil at different $\mathrm{pH}$ values should also be evaluated experimentally. The concentration of enhancement agent required must also be carefully determined from the laboratory investigations. An improper choice of enhancement agent may aggravate the contamination problem and make the remediation process much more difficult (Yeung et al., 1996).

As enhancement agents are contaminant-specific, it is difficult to use a single agent for cleanup of a site contaminated by multiple contaminants. The technique of sequentially enhanced electrokinetic extraction was proposed by Reddy and Chinthamreddy (2003b). Their experimental results indicated different metallic contaminants and/or contaminants of different chemical states could be removed by electrokinetic extraction using appropriate enhancement agents in a sequential manner. The same technique can be applied in chemical analyses to determine concentrations of metallic contaminants of different chemical states (Reddy et al., 2001; Suèr et al., 2003).

The results of Li et al. (2000), and Reddy and Saichek (2003) indicated the use of surfactants, and a cosolvent could effectively solubilize organic contaminants sorbed on the organic matter of soil during electrokinetic remediation. Experimental results of Ko et al. (2000) on the removal of phenanthrene from kaolinite also indicated phenanthrene removal was most efficient when using hydroxypropyl- $\beta$-cyclodextrin as a hydrophobic organic contaminant solubility-enhancing agent under proper $\mathrm{pH}$ control. Similar findings on surfactant enhancement are also reported by Kim and Lee (1999).

Reservoir conditioning. Various techniques have been developed to condition electrode reservoir solutions so as to eliminate the adverse impacts of electrode reactions. The primary purpose of electrode reservoir conditioning is to maintain reservoir solutions at an appropriate $\mathrm{pH}$ specific to the contaminants being removed. Such conditioning is particularly important for the electrokinetic remediation of soils of low acid/base buffer capacity.

Weak acids may be introduced at the cathode reservoir to neutralize hydroxide ions generated by the electrolytic reduction of water (Acar and Alshawabkeh, 1993; Pup- pala et al., 1997). However, the improper use of some acids in the process may pose a health hazard. For example, the use of hydrochloric acid may pose a health hazard as: (1) it may increase the chloride concentration in the groundwater; (2) it may promote the formation of some insoluble chloride salts, for example, lead chloride; and (3) if it reaches the anode reservoir, chlorine gas will be generated by electrolysis.

Acetic acid is a weak acid that undergoes partial dissociation in water. There are several advantages in using acetic acid to depolarize hydroxide ions generated by the cathodic electrolytic reduction processes: (1) most metal acetates are highly soluble; (2) the concentration of ions generated by acid dissociation is very low due to the high pKa value of acetic acid, and thus, the electrical conductivity of the soil will not increase drastically; (3) it is environmentally safe and biodegradable; and (4) acetate ions will prevent the formation of other insoluble salts in the vicinity of the cathode, preventing the development of a low electrical conductivity zone and dissipation of excessive electrical energy in the soil near the cathode. The experimental results of Rødsand et al. (1995) indicated depolarization of the cathode reaction by acetic acid could enhance electrokinetic extraction of lead. Reed $e t$ al. (1995) evaluated the effect of electrode reservoir conditioning on the electrokinetic extraction of lead using $1 \mathrm{M}$ acetic acid at the cathode, $0.1 \mathrm{~N}$ or $0.01 \mathrm{~N}$ hydrochloric acid at the anode, or EDTA at the cathode. Their experimental results indicated the addition of acetic acid to the cathode reservoir prevented the development of basic conditions in the soil. The technique could increase both the viable remediation period and the removal efficiency of heavy metals. The soil $\mathrm{pH}$ nearest to the cathode was lowered from 10 to 3.5. Saichek and Reddy (2003) demonstrated the use of sodium hydroxide to control $\mathrm{pH}$ at the anode could improve electrokinetic removal efficiency of phenanthrene from kaolin soil. Experimental results on the removal of lead from kaolinite by Lee and Yang (2000) indicated external circulation of the electrolyte solution from the cathode reservoir to the anode reservoir could control pore fluid $\mathrm{pH}$ and prevent excessive $\mathrm{H}^{+}$from decreasing electro-osmotic flow rate and excessive $\mathrm{OH}^{-}$from increasing heavy metal precipitation. Results on the removal of zinc from Georgia kaolinite as presented by Hicks and Tondorf (1994) indicated problems related to isoelectric focusing could be prevented by rinsing away the hydroxide ions generated at the cathode, with $95 \%$ zinc removal being achieved. Buffer solutions have also been successfully used to control the $\mathrm{pH}$ of electrode reservoir solutions so as to control the electro-osmotic fluid flow direction and maintain the electro-osmotic fluid volume flow rate (Yeung et al., 1996; Hsu, 1997; Ko et al., 2000; Yeung and Hsu, 2005). 
Another technique of reservoir conditioning is the use of ion-selective membranes to isolate specific ions generated by electrode reactions from the soil. The results of Li et al. (1998) indicated the use of a cation selective membrane at the front of the cathode to prevent hydroxide ion migration towards the anode could greatly enhance the efficiency of copper removal by electrokinetics. However, the experimental results of Rødsand et al. (1995) indicated this membrane extraction technique did not enhance electrokinetic extraction of lead as expected.

Ek-Fenton process. The feasibility of coupling electrokinetic extraction with a Fenton-like treatment process using a permeable reactive wall of scrap iron powder to remove and oxidize organic contaminants has been investigated experimentally by researchers of the National Sun Yat-sen University of Taiwan (Yang and Long, 1999; Yang and Liu, 2001).

The Fenton reaction involves two steps: (1) decomposition of $\mathrm{H}_{2} \mathrm{O}_{2}$ catalyzed by $\mathrm{Fe}$ (II) or other transition elements resulting in the generation of hydroxide radicals; and (2) degradation of organic pollutants by hydroxide radicals via oxidation. Since the hydroxide radical is well known for its nonspecific and strong oxidizing capability, the Fenton process is widely used for the destruction of biorefractory organic pollutants such as phenol, chlorophenols, nitrophenols, PAHs, PCE, nitrobenzene, etc. Although various organic compounds in soils can be degraded and destroyed by this advanced oxidation process, the employment of the process for soil remediation is in general limited to ex situ in-tank reactions. Recently, a Fenton-like reaction using zero-valent iron instead of $\mathrm{Fe}$ (II) has been found to be effective in the degradation of organic contaminants in wastewater and soil (Yang and Long, 1999). In addition, zero-valent iron has also been successfully employed as a material in permeable reactive walls for the remediation of contaminated groundwater (Palmer, 2001).

The results of bench-scale laboratory experiments performed by Yang and Liu (2001), and Yang and Long (1999) indicated it was feasible to combine electrokinetic extraction and the Fenton-like process using a permeable reactive wall of granular scrap iron powder for in situ treatment of TCE and phenols in soils. The overall contaminant remediation efficiency is contributed by two mechanisms: (1) organic contaminant destruction by the Fenton-like process; and (2) contaminant removal by electrokinetic extraction. Their experimental results also indicated the percentage of organic contaminant destruction increased with the quantity of scrap iron powder used in the process. However, a larger quantity of scrap iron powder embedded in the soil cell would lower the coefficient of electro-osmotic conductivity, resulting in a de- crease in contaminant removal efficiency by electrokinetics. Moreover, the smaller the granular size of the scrap iron powder, the higher the destruction efficiency but the lower the overall contaminant remediation efficiency.

\section{NEOCHIM process}

The NEOCHIM technology was developed by the U.S. Geological Survey on the basis of Russian scientists' research results on CHIM, a method of electrogeochemical sampling for use in the exploration of buried mineral deposits. Design, development and testing of the NEOCHIM electrode are detailed in Leinz et al. (1998a).

The technology obviates the $\mathrm{H}^{+}$and $\mathrm{OH}^{-}$problems by using an electrode made of two compartments linked by a salt bridge. The conducting electrode is immersed in a conducting fluid in the inner compartment where $\mathrm{H}^{+}$ and $\mathrm{OH}^{-}$produced by electrolysis are retained and prevented from reaching the outer compartment by the salt bridge. The salt bridge is retained by a semipermeable parchment membrane at the base of the inner compartment. A further conducting fluid is retained by the outer compartment. A schematic of the NEOCHIM electrode is shown in Fig. 2. Electrical contact of the electrode with the soil is made through a semipermeable parchment membrane at the base of the outer compartment. The membrane allows the passage of ions from the conduct-

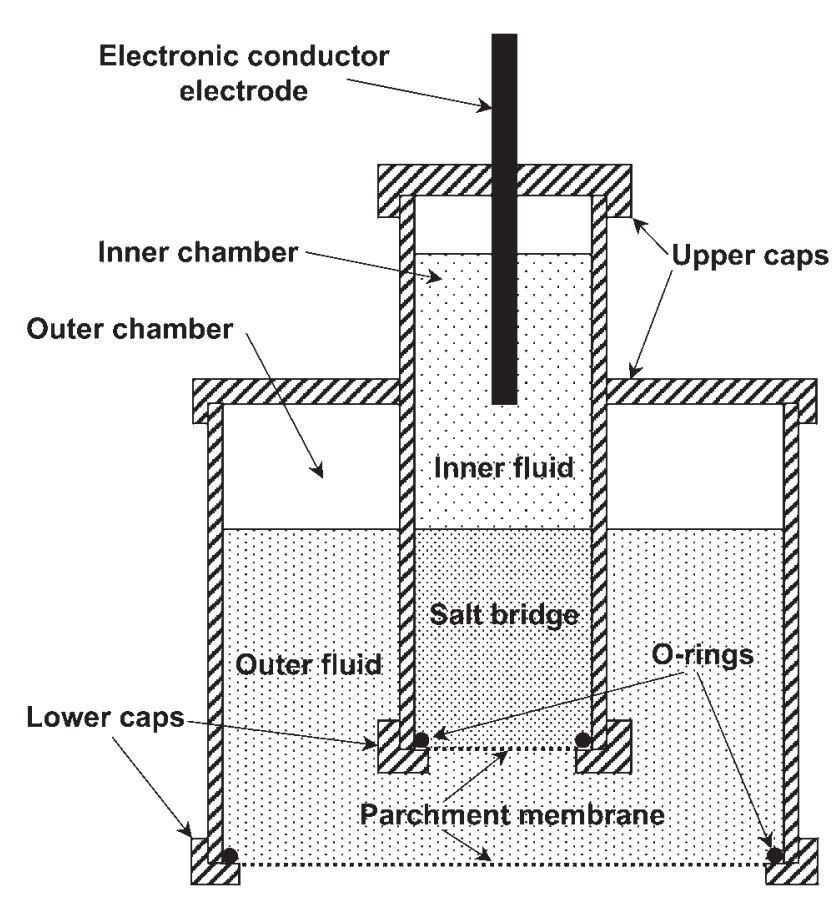

Figure 2. The NEOCHIM electrode (after Leinz et al., 1998b). 
ing fluid into the soil and from the soil into the fluid, while retaining the fluid in the compartment. It has been reported that the electrode works in electrogeochemical sampling with an efficiency ranging from 25 to $35 \%$. Experimental results of Leinz et al. (1998b) on electrokinetic extraction also indicated the high potential of the NEOCHIM process for the monitoring and remediation of hazardous wastes.

Lasagna process. The Lasagna process is an in situ remediation technique that applies the concept of Integrated In situ Remediation (Ho et al. 1995). Electrokinetics is coupled with sorption/degradation of contaminants in treatment zones that are installed directly in contaminated soils. A direct-current electric field is applied to mobilize contaminants from the contaminated soils into treatment zones where the contaminants are removed by adsorption, immobilization, or degradation as shown in Fig. 3. The technique is called Lasagna due to the layered appearance of electrodes and treatment zones, and conceptually, it can treat organic and inorganic contamination as well as mixed wastes. Electrodes and treatment zones can be of any orientation depending upon the emplacement technology used and the site-contaminant charac-
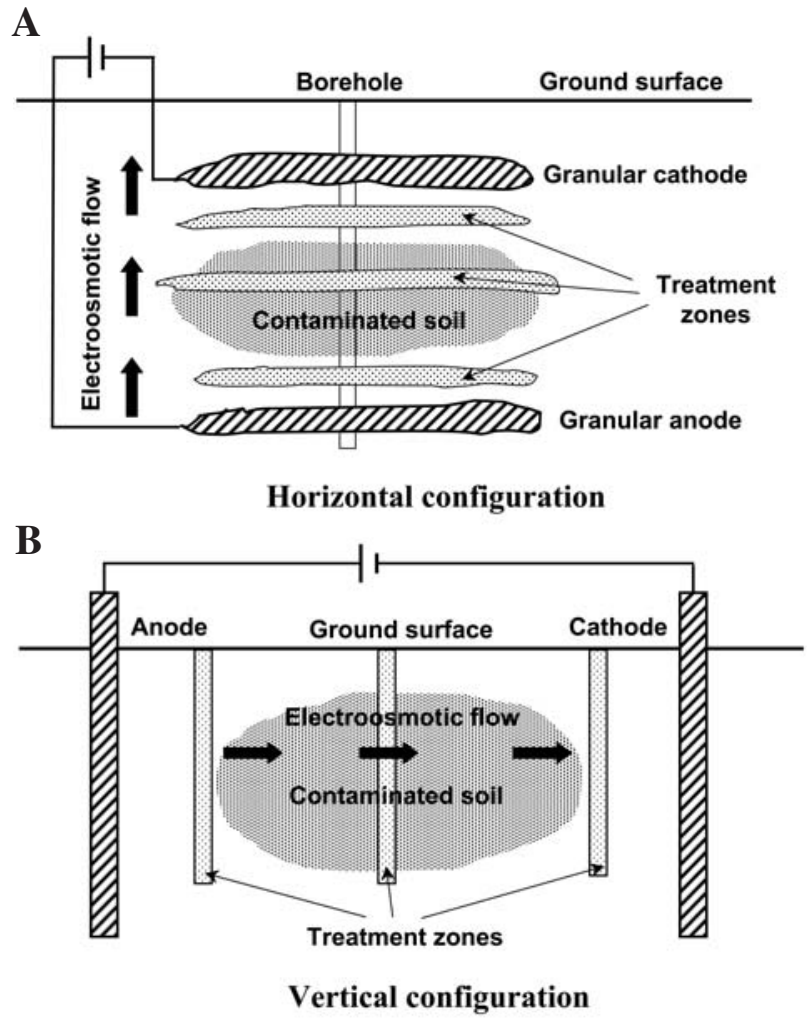

Figure 3. Principle of the Lasagna process (after Ho et al., 1995). teristics. The process has the following components (Ho et al., 1995):

1. Installation of treatment zones: highly permeable zones in close proximity are created through the contaminated soils by hydrofracturing or similar technologies. Appropriate materials such as sorbents, catalytic agents, microbes, oxidants, buffers, etc., are added to these highly permeable zones to transform them into treatment zones. In the horizontal configuration, graphite particles can be injected above and below contaminated soils during the hydrofracturing process to form in-place granular electrodes.

2. Transport of contaminants: electrokinetics is utilized to transport contaminants from the soil into the treatment zones. Since these zones are located close to one another, the time taken for the contaminants to move from zone to zone can be very short.

3. Treatment of contaminants: for highly nonpolar contaminants, surfactants can be introduced into the fluid or incorporated into the treatment zones to solubilize the organics. For a mixture of organics and metals, the treatment zones can contain sorbents for binding the metals and/or microbes or catalysts for degrading the organics.

4. If needed, the fluid flow direction can be reversed periodically by switching electrical polarity. The operation would enable multiple passes of the contaminants through the treatment zones for complete sorption/destruction. The polarity reversal also serves to minimize complications associated with long-term operation of unidirectional electrokinetic processes. The high $\mathrm{pH}$ cathode effluent (high $\mathrm{pH}$ ) can be recirculated through the contaminated soil when the polarity of the electric field applied is reversed, that is, the cathode has been reversed to become the anode and vice versa. The recycling of effluent provides a convenient means for $\mathrm{pH}$ neutralization of the contaminated soil and minimization of wastewater generation.

The technique has been proved feasible in bench-scale laboratory experiments on the degradation of para-nitrophenol in kaolinite (Ho et al., 1995) and field-scale experiments on the remediation of trichloroethylene (TCE) contaminated soils at various sites (Ho et al., 1997, 1999a, 1999b; Roulier et al., 2000).

Bioelectrokinetic remediation. Rabbi et al. (2000) explored the feasibility of using benzoic acid, a bioremediation cometabolite for TCE degradation, to enhance the biodegradation of TCE. Benzoic acid was injected by both electro-osmosis (neutral benzoic acid) and ionic migration (the benzoate anion). Their experimental results 
demonstrated the feasibility in principle for using electrokinetic injection to engineer the degradation of recalcitrant hydrocarbons, or other difficult to degrade contaminants, that is, bioelectrokinetic remediation.

The combination of bioleaching and electrokinetics for the remediation of metal contaminated soil was investigated by Maini et al. (2000a). In bioleaching, indigenous sulfur-oxidizing bacteria convert reduced sulfur compounds to sulfuric acid, acidifying soil, and mobilizing metal ions. Experimental results on remediation of copper contaminated soil by Maini et al. (2000a) indicated the effectiveness of electrokinetic extraction was enhanced by preacidification of the contaminated soil by sulfur-oxidizing bacteria. The electrokinetic treatment also appeared to stimulate the activity of sulfuroxidizing bacteria by the removal of inhibitory ions and other positive effects of the electric current upon soil microbial activities. The experimental results of Lear et al. (2004) also indicated the application of electrokinetics had no serious negative effect on soil microbial health with the exception of soil close to the anode where the environment was acidic. The synergistic methodology appears to be promising for a range of contaminated sites including former gasworks and wastes from mining.

Ek-phytoremediation process. The use of a combination of electrokinetic remediation and phytoremediation to decontaminate soils contaminated by copper, cadmium, and arsenic was investigated by O'Connor et al. (2003) in laboratory-scale reactors. Phytoremediation is defined as the use of plants to remove, degrade, or sequester inorganic and organic contaminants from soil and/or groundwater. Phytoremediation technologies include phytostabilization and phytoextraction. Phytostabilization is the physical stabilization of contaminants and prevention of their reentrainment to adjacent ecosystems. Phytoextraction is the removal of heavy metals from soil by plants, resulting in metal uptake, transport, and concentration in plant tissues. Their results demonstrated the application of a direct-current electric field current could migrate metallic contaminants from the anode towards the cathode, accompanied by significant changes in soil $\mathrm{pH}$. Moreover, perennial ryegrass could be grown in the treated soils, taking up a proportion of the mobilized metals into its shoot system.

\section{NUMERICAL MODELING}

Many numerical models have been developed to simulate various aspects of electrokinetic extraction including transport and fate of contaminants, pore pressure dis- tribution, electrical voltage distribution, electric current density, migration of acid front, electrochemical reactions, soil-contaminant interactions, etc. These models are developed on the basis of different assumptions on the electrochemical processes during electrokinetic remediation, different numerical schemes, etc. They can predict specific bench-scale laboratory experimental results with varying degrees of success. Although numerical simulation of electrokinetic extraction is beyond the scope of this review paper, a comprehensive list of references is included for further research by interested readers. These useful references include Yeung (1990), Alshawabkeh and Acar (1992, 1996), Eykholt $(1992,1997)$, Datla (1994), Eykholt and Daniel (1994), Hicks and Tondorf (1994), Jacobs et al. (1994), Choi and Lui (1995), Yeung and Datla (1995), Denisov et al. (1996), Menon (1996), Yu and Neretnieks (1996, 1997), Haran et al. (1997), Liu and Lui (1997), Ribeiro and Mexia (1997), Kim (1998), Jennings and Mansharamani (1999), Narasimhan and Ranjan (2000), Shiba et al. (2000), Mattson et al. (2002a, 2002b), Rahner et al. (2002), Röhrs et al. (2002), Kim et al. (2003), Musso (2003), Oyanader et al. (2003), Vereda-Alonso et al. (2004), among many others.

\section{CONCLUSIONS}

Electrokinetic extraction is an emerging remediation technology applicable to fine-grained soils of low hydraulic conductivity and large specific area. It feasibility has been proven by many bench-scale laboratory experiments and pilot-scale field studies. Soil type, and contaminant type and concentration do not pose any significant limitations on the applicability of the technology. In fact, it can be used to remove contaminants uniformly from a heterogeneous natural deposit. Moreover, it can be effectively coupled with other soil remediation technologies to improve the overall remediation efficiency.

As with many other remediation technologies, electrokinetic extraction has its own drawbacks including: (1) migration of contaminants is not highly selective; (2) acidification of soils to promote mobility of contaminants may not be technically feasible and/or environmentally acceptable; (3) the technology is not very cost-effective when the target contaminant concentration is low and the background nontarget ion concentration is high; among many others.

Successful application of the technology primarily depends on mobility of the contaminant in the soil matrix. Factors affecting the extractability of contaminants by electrokinetics are discussed in detail. Various enhancement techniques in different stages of development are 
also included to promote further discussion and future research. A comprehensive list of references is compiled for use by readers interested in the subject.

\section{REFERENCES}

ACAR, Y.B., and ALSHAWABKEH, A. (1993). Principles of electrokinetic remediation. Environ. Sci. Technol. 27(13), 2638-2647.

ACAR, Y.B., and ALSHAWABKEH, A.N. (1996). Electrokinetic remediation. 1. Pilot-scale tests with $\mathrm{Pb}$-spiked kaolinite. ASCE J. Geotech. Eng. 122(3), 173-185.

ACAR, Y.B., LI, H., and GALE, R.J. (1992). Phenol removal from kaolinite by electrokinetics. ASCE J. Geotech. Eng. 118(11), 1837-1852.

ACAR, Y.B., HAMED, J.T., ALSHAWABKEH, A., and GALE, R.J. (1994). Cd(II) removal from saturated kaolinite by application of electrical current. Géotechnique 44(3), 239-254.

ACAR, Y.B., RABBI, M.F., and OZSU, E.E. (1997). Electrokinetic injection of ammonium and sulfate ions into sand and kaolinite beds. ASCE J. Geotech. Geoenviron. Eng. 123(3), 239-249.

AGARD, J.B.R. (1981). A study of electro-reclamation and its application to the removal of toxic metals from contaminated soils. MSc thesis, Univ. of Manchester, England.

ALBERTY, R.A. (1983). Physical Chemistry, 6th ed. New York: John Wiley \& Sons.

ALSHAWABKEH, A., and ACAR, Y.B. (1992). Removal of contaminants from soils by electrokinetics: A theoretical treatise. J. Environ. Sci. Health A27(7), 1835-1861.

ALSHAWABKEH, A.N., and ACAR, Y.B. (1996). Electrokinetic remediation. 2. Theoretical model. ASCE J. Geotech. Eng. 122(3), 186-196.

ALSHAWABKEH, A.N., PUPPALA, S.K., ACAR, Y.B., GALE, R.J., and BRICKA, M. (1997). Effect of solubility on enhanced electrokinetic extraction of metals. In J.C. Evans, Ed., In Situ Remediation of the Geoenvironment (Geotech. Spec. Publ. No. 71). Reston, VA: ASCE, pp. 532-544.

ALSHAWABKEH, A.N., YEUNG, A.T., and BRICKA, M.R. (1999). Practical aspects of in-situ electrokinetic extraction. ASCE J. Environ. Eng. 125(1), 27-35.

ANDERSON, J.L., and IDOL, W.K. (1985). Electroosmosis through pores with nonuniformly charged walls. Chem. Eng. Commun. 38(3), 93-106.

AZZAM, R., and OEY, W. (2001). The utilization of electrokinetics in geotechnical and environmental engineering. Transport Porous Med. 42(3), 293-314.
BARAUD, F., TELLIER, S., and ASTRUC, M. (1997). Ion velocity in soil solution during electrokinetic remediation. $J$. Hazard. Mater. 56(3), 315-332.

BRUELL, C.J., SEGALL, B.A., and WALSH, M.T. (1992). Electroosmotic removal of gasoline hydrocarbons and TCE from clay. ASCE J. Environ. Eng. 118(1), 68-83.

BUDHU, M., RUTHERFORD, M., SILLS, G., and RASMUSSEN, W. (1997). Transport of nitrates through clay using electrokinetics. ASCE J. Environ. Eng. 123(12), 1251-1253.

CHEN, J-L., and MURDOCH, L. (1997). Field demonstration of in situ electroosmosis between horizontal electrodes. In J.C. Evans, Ed., In Situ Remediation of the Geoenvironment (Geotech. Spec. Publ. No. 71) Reston, VA: ASCE, pp. 545-559.

CHEN, J.-L., AL-ABED, S.R., BRYNDZIA, L.T., and MURDOCH, L. (1999). Cation transport and partitioning during a field test of electroosmosis. Water Resour. Res. 35(12), 3841-3851.

CHINTHAMREDDY, S., and REDDY, K.R. (1999). Oxidation and mobility of trivalent chromium in manganese-enriched clays during electrokinetic remediation. J. Soil. Contam. 8(2), 197-216.

CHOI, Y.S., and LUI, R. (1995). A mathematical-model for the electrokinetic remediation of contaminated soil. J. Hazard. Mater. 44(1), 61-75.

CHUNG, H.I., and KANG, B.H. (1999). Lead removal from contaminated marine clay by electrokinetic soil decontamination. Eng. Geol. 53(2), 139-150.

CHUNG, M. (1995). Sealing impoundment leaks by electrophoresis. PhD dissertation, Dept. of Civ. Eng., Texas A\&M Univ., College Station, TX.

COLETTA, T.F., BRUELL, C.J., RYAN, D.K., and INYANG, H.I. (1997). Cation-enhanced removal of lead from kaolinite by electrokinetics. ASCE J. Environ. Eng. 123(12), 1227-1233.

COX, C.D., SHOESMITH, M.A., and GHOSH, M.M. (1996). Electrokinetic remediation of mercury-contaminated soils using iodine/iodide lixiviant. Environ. Sci. Technol. 30(6), 1933-1938.

CURTIN, D., CAMPBELL, C.A., and MESSER, D. (1996). Prediction of titrable acidity and soil sensitivity to $\mathrm{pH}$ change. J. Environ. Qual. 25(6), 1280-1284.

DARMAWAN, and WADA, S.I. (2002). Effect of clay mineralogy on the feasibility of electrokinetic soil decontamination technology. Appl. Clay Sci. 20(6), 283-293.

DATLA, S. (1994). A unified theory on electro-kinetic extraction of contaminants. MSc thesis, Dept. of Civ. Eng., Texas A\&M Univ., College Station, TX.

DeFLAUN, M.F., and CONDEE, C.W. (1997). Electrokinetic transport of bacteria. J. Hazard. Mater. 55(1-3), 263-277. 
DENISOV, G., HICKS, R.E., and PROBSTEIN, R.F. (1996). On the kinetics of charged contaminant removal from soils using electric fields. J. Colloid Interface Sci. 178(1), 309-323.

DZENITIS, J.M. (1997). Soil chemistry effects and flow prediction in electroremediation of soil. Environ. Sci. Technol. 31(4), 1191-1197.

ELZAHABI, M., and YONG, R.N. (2001). pH influence on sorption characteristics of heavy metal in the vadose zone. Eng. Geol. 60(1-4), 61-68.

EYKHOLT, G.R. (1992). Driving and complicating features of electrokinetic treatment of soils. $\mathrm{PhD}$ dissertation, Dept. of Civ. Eng., Univ. of Texas at Austin, TX.

EYKHOLT, G.R. (1997). Development of pore pressures by nonuniform electroosmosis in clays. J. Hazard. Mater. 55(1-3), 171-186.

EYKHOLT, G.R., and DANIEL, D.E. (1994). Impact of system chemistry on electroosmosis in contaminated soil. ASCE J. Geotech. Eng. 120(5), 797-815.

GIBBS, H.J. (1966). Research on electroreclamation of salinealkali soils. Tran. Am. Soc. Agricult. Eng. 9(2), 164-169.

GOPINATH, S. (1994). A laboratory study of electro-kinetic remediation of fine-grained soil contaminated with organic compounds. MSc thesis, Dept. of Civ. Eng., Texas A\&M Univ., College Station, TX.

GRUNDL, T., and REESE, C. (1997). Laboratory study of electrokinetic effects in complex natural sediments. J. Hazard. Mater. 55(1-3), 187-201.

HAMED, J. (1990). Decontamination of soil using electroosmosis. PhD thesis, Dept. of Civ. Eng., Louisiana State Univ., Baton Rouge, LA.

HAMED, J., ACAR, Y.B., and GALE, R.J. (1991). Pb(II) removal from kaolinite using electrokinetics. ASCE J. Geotech. Eng. 117(2), 241-271.

HAMED, J.T., and BHADRA, A. (1997). Influence of current density and $\mathrm{pH}$ on electrokinetics. J. Hazard. Mater. 55(1-3), 279-294.

HAMNETT, R. (1980). A study of the processes involved in the electro-reclamation of contaminated soils. MSc dissertation, University of Manchester, England.

HANSEN, H.K., OTTOSEN, L.M., KLIEM, B.K., and VILLUMSEN, A. (1997). Electrodialytic remediation of soils polluted with $\mathrm{Cu}, \mathrm{Cr}, \mathrm{Hg}, \mathrm{Pb}$ and $\mathrm{Zn}$. J. Chem. Tech. Biotechnol. 70(1), 67-73.

HARAN, B.S., POPOV, B.N., ZHENG, G., and WHITE, R.E. (1996). Development of a new electrochemical technique for decontamination of hexavalent chromium from low surface charged soils. AIChE Environ. Prog. 15(3), 166-172.
HARAN, B.S., POPOV, B.N., ZHENG, G., and WHITE, R.E. (1997). Mathematical modeling of hexavalent chromium decontamination from low surface charged soils. J. Hazard. Mater. 55(1-3), 93-107.

HICKS, R.E., and TONDORF, S. (1994). Electrorestoration of metal contaminated soils. Environ. Sci. Technol. 28(12), 2203-2210.

HO, S.V., SHERIDAN, P.W., ATHMER, C.J., HEITKAMP, M.A., BRACKIN, J.M., WEBER, D., and BRODSKY, P.H. (1995). Integrated in situ soil remediation technology: The Lasagna process. Environ. Sci. Technol. 29(10), 2528-2534.

HO, S.V., ATHMER, C., SHERIDAN, P.W., HUGHES, B.M., ORTH, R., MCKENZIE, D., BRODSKY, P.H., SHAPIRO, A., THORNTON, R., SALVO, J., et al. (1999a). The Lasagna technology for in situ soil remediation. 1. Small field test. Environ. Sci. Technol. 33(7), 1086-1091.

HO, S.V., ATHMER, C., SHERIDAN, P.W., HUGHES, B.M., ORTH, R., MCKENZIE, D., BRODSKY, P.H., SHAPIRO, A.M., SIVAVEC, T.M., SALVO, J., et al. (1999b). The Lasagna technology for in situ soil remediation. 2. Large field test. Environ. Sci. Technol. 33(7), 1092-1099.

HO, S.V., ATHMER, C.J., SHERIDAN, P.W., and SHAPIRO, A.P. (1997). Scale-up aspects of the Lasagna (TM) process for in situ soil decontamination. J. Hazard. Mater. 55(1-3), 39-60.

HSU, C. (1997). Electrokinetic remediation of heavy metal contaminated soils. $\mathrm{PhD}$ dissertation, Dept. of Civ. Eng., Texas A\&M Univ., College Station, TX.

HUNTER, R.J. (1981). Zeta Potential in Colloid Science: Principles and Applications. London: Academic Press.

HUNTER, R.J., and JAMES, M. (1992). Charge reversal of kaolinite by hydrolyzable metal ions: An electroacoustic study. Clays Clay Miner. 40(6), 644-649.

HWANG, S., RAMIREZ, N., CUTRIGHT, T.J., and JU, L.-K. (2003). The role of soil properties in pyrene sorption and desorption. Water Air, Soil Pollut. 143(1-4), 65-80.

IYER, R. (2001). Electrokinetic remediation. Particul. Sci. Technol. 19(3), 219-228.

JACKMAN, S.A., MAINI, G., SHARMAN, A.K., SUNDERLAND, G., and KNOWLES, C.J. (2001). Electrokinetic movement and biodegradation of 2,4-dichlorephenoxyacetic acid in silt soil. Biotechnol. Bioeng. 74(1), 40-48.

JACOBS, R.A., SENGUIN, M.Z., HICKS, R.E., and PROBSTEIN, R.F. (1994). Model and experiments on soil remediation by electric fields. J. Environ. Sci. Health A29(9), 1933-1955.

JENNINGS, A.A., and MANSHARAMANI, P. (1999). Modeling electrokinetically-enhanced aggregate remediation. Environ. Model. Softw. 14(6), 625-634. 
KELSH, D.J., and PARSONS, M.W. (1997). Department of energy sites suitable for electrokinetic remediation. J. Hazard. Mater. 55(1-3), 109-116.

KHARKATS, Y.I. (1998). Theoretical model of radionuclide extraction from soils by the mechanism of ionic electromigration. J. Electroanal. Chem. 450(1), 27-35.

KIM, G. (1998). Two-dimensional numerical modeling of electrokinetic extraction of contaminants from fine-grained soils. PhD dissertation, Dept. of Civ. Eng., Texas A\&M Univ., College Station, TX.

KIM, J., and LEE, K. (1999). Effects of electric field directions on surfactant enhanced electrokinetic remediation of dieselcontaminated sand column. J. Environ. Sci. Health A34(4), 863-877.

KIM, S.O., MOON, S.H., and KIM, K.W. (2001). Removal of heavy metals from soils using enhanced electrokinetic soil processing. Water Air Soil Pollut. 125(1), 259-272.

KIM, S.O., KIM, K.W., and STUBEN, D. (2002a). Evaluation of electrokinetic removal of heavy metals from tailing soils. ASCE J. Environ. Eng. 128(8), 705-715.

KIM, S.O., MOON, S.H., KIM, K.W., and YUN, S.T. (2002b). Pilot scale study on ex situ electrokinetic removal of heavy metals from municipal wastewater sludges. Water Res. 36(19), 4765-4774.

KIM, S.O., KIM, J.J., YUN, S.T., and KIM, K.W. (2003). Numerical and experimental studies on cadmium(II) transport in kaolinite clay under electrical fields. Water Air Soil Pollut. 150(1-4), 135-162.

KIM, S.S., and HAN, S.J. (2003). Application of an enhanced electrokinetic ion injection system to bioremediation. Water Air Soil Pollut. 146(1-4), 365-377.

KO, S.O., SCHLAUTMAN, M.A., and CARRAWAY, E.R. (2000). Cyclodextrin-enhanced electrokinetic removal of phenanthrene from a model clay soil. Environ. Sci. Technol. 34(8), 1535-1541.

KUO, C.C., and PAPADOPOULOS, K.D. (1996). Electrokinetic movement of settled spherical particles in fine capillaries. Environ. Sci. Technol. 30(4), 1176-1179.

LAGEMAN, R. (1993). Electro-reclamation (applications in The Netherlands). Environ. Sci. Technol. 27(13), 26482650 .

LAURSEN, S. (1997). Laboratory investigation of electroosmosis in bentonites and natural clays. Can. Geotech. J. 34(5), 664-671.

LEAR, G., HARBOTTLE, M.J., VAN DER GAST, C.J., JACKMAN, S.A., KNOWLES, C.J., SILLS, G., and THOMPSON, I.P. (2004). The effect of electrokinetics on soil microbial communities. Soil Biol. Biochem. 36(11), 1751-1760.
LEE, H.H., and YANG, J.W. (2000). A new method to control electrolytes $\mathrm{pH}$ by circulation system in electrokinetic soil remediation. J. Hazard. Mater. 77(1-3), 227-240.

LEE, H.S., and LEE, K. (2001). Bioremediation of diesel-contaminated soil by bacterial cells transported by electrokinetics. J. Microbiol. Biotech. 11(6), 1038-1045.

LEINZ, R.W., HOOVER, D.B., FEY, D.L., SMITH, D.B., and PATTERSON, T. (1998a). Electro-geochemical sampling with NEOCHIM-Results of tests over buried gold deposits. J. Geochem. Explor. 61(1-3), 57-86.

LEINZ, R.W., HOOVER, D.B., and MEIER, A.L. (1998b). NEOCHIM: An electrochemical method for environmental application. J. Geochem. Explor. 64(1-3), 421-434.

LI, A., CHEUNG, K.A., and REDDY, K.R. (2000). Cosolventenhanced electrokinetic remediation of soils contaminated with phenanthrene. ASCE J. Environ. Eng. 126(6), 527-533.

LI, R.S., and LI, L.Y. (2000). Enhancement of electrokinetic extraction from lead-spiked soils. ASCE J. Environ. Eng. 126(9), 849-857.

LI, Z., YU, J.-W., and NERETNIEKS, I. (1997). Removal of $\mathrm{Pb}(\mathrm{II}), \mathrm{Cd}(\mathrm{II})$ and $\mathrm{Cr}(\mathrm{III})$ from sand by electromigration. $J$. Hazard. Mater. 55(1-3), 295-304.

LI, Z., YU, J.-W., and NERETNIEKS, I. (1998). Electroremediation: Removal of heavy metals from soils by using cation selective membrane. Environ. Sci. Technol. 32(3), 394-397.

LIU, B.Y., and LUI, R. (1997). Electrokinetic remediation of contaminated soil. Nonlinear Anal. 30(6), 3391-3398.

LORENZ, P.B. (1969). Surface conductance and electrokinetic properties of kaolinite beds. Clays Clay Miner. 17(4), 223-231.

MAINI, G., SHARMAN, A.K., SUNDERLAND, G., KNOWLES, C.J., and JACKMAN, S. (2000a). An integrated method incorporating sulfur-oxidising bacteria and electrokinetics to enhance removal of copper from contaminated soil. Environ. Sci. Technol. 34(6), 1081-1087.

MAINI, G., SHARMAN, A.K., KNOWLES, C.J., SUNDERLAND, G., and JACKMAN, S.A. (2000b). Electrokinetic remediation of metals and organics from historically contaminated soil. J. Chem. Technol. Biot. 75(8), 657-664.

MATTSON, E.D., BOWMAN, R.S., and LINDGREN, E.R. (2000). Electrokinetic remediation using surfactant-coated ceramic casings. ASCE J. Environ. Eng. 126(6), 534-540.

MATTSON, E.D., BOWMAN, R.S., and LINDGREN, E.R. (2002a). Electrokinetic ion transport through unsaturated soil: 1. Theory, model development, and testing. J. Contam. Hydrol. 54(1-2), 99-120.

MATTSON, E.D., BOWMAN, R.S., and LINDGREN, E.R. (2002b). Electrokinetic ion transport through unsaturated 
soil: 2. Application to a heterogeneous field site. J. Contam. Hydrol. 54(1-2), 121-140.

McBRIDE, M. B. (1994). Environmental Chemistry of Soils. New York: Oxford University Press.

MENON, R.M. (1996). Numerical modeling and experimental study on electro-kinetic extraction. $\mathrm{PhD}$ dissertation, Dept. of Civ. Eng., Texas A\&M Univ., College Station, TX.

MILLER, S.E., and LOW, P.F. (1990). Characterization of the electrical double layer of montmorillonite. Langmuir 6(3), $572-578$.

MITCHELL, J.K. (1991). Conduction phenomena: From theory to geotechnical practice. Géotechnique 41(3), 299-340.

MITCHELL, J.K. (1993). Fundamentals of Soil Behavior, 2nd ed. New York: John Wiley \& Sons.

MOHAMED, A.M.O. (1996). Remediation of heavy metal contaminated soils via integrated electrochemical processes. Waste Manage. 16(8), 741-747.

MULLIGAN, C.N., YONG, R.N., and GIBBS, B.F. (2001). Remediation technologies for metal-contaminated soils and groundwater: An evaluation. Eng. Geol. 60(1-4), 193-207.

MURDOCH, L.V., and CHEN, J-L. (1997). Effects of conductive fractures during in-situ electroosmosis. J. Hazard. Mater. 55(1-3), 239-262.

MUSSO, G. (2003). Transport phenomena in electrokinetic soil remediation. Math. Comput. Model. 37(5-6), 589-594.

NARASIMHAN, B., and RANJAN, R.S. (2000). Electrokinetic barrier to prevent subsurface contaminant migration: Theoretical model development and validation. J. Contam. Hydrol. 42(1), 1-17.

O'CONNOR, C.S., LEPP, N.W., EDWARDS, R., and SUNDERLAND, G. (2003). The combined use of electrokinetic remediation and phytoremediation to decontaminate metalpolluted soils: A laboratory-scale feasibility study. Environ. Monit. Assess. 84(1-2), 141-158.

OTTOSEN, L.M., HANSEN, H.K., LAURSEN, S., and VILLUMSEN, A. (1997). Electrodialytic remediation of soil polluted with copper from wood preservation industry. Environ. Sci. Technol. 31(6), 1711-1715.

OTTOSEN, L.M., HANSEN, H.K., and HANSEN, C.B. (2000). Water splitting at ion-exchange membranes and potential differences in soil during electrodialytic soil remediation. J. Appl. Electrochem. 30(11), 1199-1207.

OTTOSEN, L.M., HANSEN, H.K., RIBEIRO, A.B., and VILLUMSEN, A. (2001). Removal of $\mathrm{Cu}, \mathrm{Pb}$ and $\mathrm{Zn}$ in an applied electric field in calcareous and non-calcareous soils. $J$. Hazard. Mater. 85(3), 291-299.

OYANADER, M.A., ARCE, P., and DZURIK, A. (2003). Avoiding pitfalls in electrokinetic remediation: Robust de- sign and operation criteria based on first principles for maximizing performance in a rectangular geometry. Electrophoresis 24(19-20), 3457-3466.

PAGE, M.M, and PAGE, C.L. (2002). Electroremediation of contaminated soils. J. Environ. Eng. ASCE 128(3), 208-219.

PAILLAT, T., MOREAU, E., GRIMAUD, P.O., and TOUCHARD, G. (2000). Electrokinetic phenomena in porous media applied to soil decontamination. IEEE Trans. Dielect. Elect. Insulat. 7(5), 693-704.

PALMER, P.L. (2001). Permeable treatment barriers. In: E.K. Nyer, Ed., In Situ Treatment Technology, Boca Raton, FL: Lewis Publishers, pp. 259-282.

PAMUKCU, S., and WITTLE, J.K. (1992). Electrokinetic removal of selected heavy metals from soil. AIChE Environ. Prog. 11(3), 241-250.

PAMUKCU, S., WEEKS, A., and WITTLE, J.K. (2004). Enhanced reduction of $\mathrm{Cr}(\mathrm{VI})$ by direct electric current in a contaminated clay. Environ. Sci. Technol. 38(4), 1236-1241.

POMÈS, V., FERNÁNDEZ, A., and HOUI, D. (2002). Effect of applied electrical field and the initial soil concentration on species recovery during application of the electroremediation process. Process Safety Environ. Protect., Trans. IChemE Part B 80(5), 256-264.

PROZOROV, L.B., SHCHEGLOV, M.Y., NIKOLAEVSKY, V.B., SHEVTSOVA, E.V., and KORNEVA, S.A. (2000). The influence of electric parameters on the dynamics of the electrokinetic decontamination of soils. J. Radioanal. Nucl. Chem. 246(3), 571-574.

PUPPALA, S.K., ALSHAWABKEH, A.N., ACAR, Y.B., GALE, R.J., and BRICKA, M. (1997). Enhanced electrokinetic remediation of high sorption capacity soil. J. Hazard. Mater. 55(1-3), 203-220.

PURI, A.N., and ANAND, B. (1936). Reclamation of alkali soils by electrodialysis. Soil Sci. 42(1), 23-27.

RABBI, M.F., CLARK, B., GALE, R.J., OZSU-ACAR, E., PARDUE, J., and JACKSON, A. (2000). In situ TCE bioremediation study using electrokinetic cometabolite injection. Waste Manage. 20(4), 279-286.

RAHNER, D., LUDWIG, G., and ROHRS, J. (2002). Electrochemically induced reactions in soils-A new approach to the in-situ remediation of contaminated soils? Part 1: The microconductor principle. Electrochim. Acta. 47(9), 13951403.

RAY, C., and RAMSEY, R.H. (1987). Removal of heavy metals in wastewater in a clay soil matrix using electro-osmosis. AIChE Environ. Prog. 6(3), 145-149.

REDDY, K.R., and PARUPUDI, U.S. (1997). Removal of chromium, nickel and cadmium from clays by in-situ electrokinetic remediation. J. Soil. Contam. 6(4), 391-407. 
REDDY, K.R., and CHINTHAMREDDY, S. (1999). Electrokinetic remediation of heavy metal-contaminated soils under reducing environments. Waste Manage. 19(4), 269-282.

REDDY, K.R., and CHINTHAMREDDY, S. (2003a). Effects of initial form of chromium on electrokinetic remediation in clays. Adv. Environ. Res. 7(2), 353-365.

REDDY, K.R., and CHINTHAMREDDY, S. (2003b). Sequentially enhanced electrokinetic remediation of heavy metals in low buffering clayey soil. ASCE J. Geotech. Geoenvir. Eng. 129(3), 263-277.

REDDY, K.R., and SAICHEK, R.E. (2003). Effect of soil type on electrokinetic removal of phenanthrene using surfactants and cosolvents. ASCE J. Environ. Eng. 129(4), 336-346.

REDDY, K.R., PARUPUDI, U.S., DEVULAPALLI, S.N., and XU, C.Y. (1997). Effects of soil composition on the removal of chromium by electrokinetics. J. Hazard. Mater. 55(1-3), 135-158.

REDDY, K.R., XU, C.Y., and CHINTHAMREDDY, S. (2001). Assessment of electrokinetic removal of heavy metals from soils by sequential extraction analysis. J. Hazard. Mater. 84(2-3), 279-296.

REDDY, K.R., CHAPARRO, C., and SAICHEK, R.E. (2003a). Iodide-enhanced electrokinetic remediation of mercury-contaminated soils. ASCE J. Environ. Eng. 129(12), 1137-1148.

REDDY, K.R., CHINTHAMREDDY, S., SAICHECK, R.E., and CUTRIGHT T.J. (2003b). Nutrient amendment for the bioremediation of a chromium-contaminated soil by electrokinetics. Energy Sources 25(9), 931-943.

REED, B.E., BERG, M.T., THOMPSON, J.C., and HATFIELD, J.H. (1995). Chemical conditioning of electrode reservoirs during electrokinetic soil flushing of $\mathrm{Pb}$-contaminated silt loam. ASCE J. Environ. Eng. 121(11), 805-815.

RIBEIRO, A.B., and MEXIA, J.T. (1997). A dynamic model for the electrokinetic removal of copper from a polluted soil. J. Hazard. Mater. 56(3), 257-271.

RØDSAND, T., ACAR, Y.B., and BREEDVELD, G. (1995). Electrokinetic extraction of lead from spiked Norwegian marine clay. In Y.B. Acar, and D.E. Daniel, Eds., Characterization, Containment, Remediation, and Performance in Environmental Geotechnics, (Geotech. Spec. Publ. No. 46) Vol. 2. New York: ASCE, pp. 1518-1534.

RÖHRS, J., LUDWIG, G., and RAHNER, D. (2002). Electrochemically induced reactions in soils-A new approach to the in-situ remediation of contaminated soils? Part 2: Remediation experiments with a natural soil containing highly chlorinated hydrocarbons. Electrochim. Acta 47(9), 14051414 .

ROULIER, M., KEMPER, M., AL-ABED, S., MURDOCH, L., CLUXTON, P., CHEN, J.-L., and DAVIS-HOOVER, W.
(2000). Feasibility of electrokinetic soil remediation in horizontal Lasagna ${ }^{\mathrm{TM}}$ cells. J. Hazard. Mater. 77(1-3), 161-176.

RUNNELLS, D.D., and LARSON, J.L. (1986). A laboratory study of electromigration as a possible field technique for the removal of contaminants from ground water. Ground Water Monit. Rev. 6(3), 85-91.

RUNNELLS, D.D., and WAHLI, C. (1993). In situ electromigration as a method for removing sulfate, metals and other contaminants from groundwater. Ground Water Monit. Remediat. 13(1), 121-129.

SAH, J.G., and CHEN, J.Y. (1998). Study of the electrokinetic process on $\mathrm{Cd}$ and $\mathrm{Pb}$ spiked soils. J. Hazard. Mater. 58(1-3), 301-315.

SAICHEK, R.E., and REDDY, K.R. (2003). Effect of pH control at the anode for the electrokinetic removal of phenanthrene from kaolin soil. Chemosphere 51(4), 273-287.

SANJAY, K., ARORA, A., SHEKHAR, R., and DAS, R.P. (2003). Electroremediation of $\mathrm{Cr}(\mathrm{VI})$ contaminated soils: Kinetics and energy efficiency. Colloids Surfaces A: Physicochem. Eng. Aspects 222(1-3), 253-259.

SAWADA, A., TANAKA, S., FUKUSHIMA, M., and TATSUMI, K. (2003). Electrokinetic remediation of clayey soils containing copper(II)-oxinate using humic acid as a surfactant. J. Hazard. Mater. 96(2-3), 145-154.

SCHULTZ, D.S. (1997). Electroosmosis technology for soil remediation: Laboratory results, field trial, and economic modeling. J. Hazard. Mater. 55(1-3), 81-91.

SCOTT, T.B. (1994). Physicochemical phenomena of electrokinetic extraction of inorganic contaminants from kaolinite. MSc thesis, Dept. of Civ. Eng., Texas A\&M Univ., College Station, TX.

SEGALL, B.A., and BRUELL, C.J. (1992). Electroosmotic contaminant-removal processes. ASCE J. Environ. Eng. 118(1), 84-100.

SHANG, J.Q. (1997). Zeta potential and electroosmotic permeability of clay soils. Can. Geotech. J. 34(4), 627-631.

SHAPIRO, A.P., and PROBSTEIN, R.F. (1993). Removal of contaminants from saturated clay by electroosmosis. Environ. Sci. Technol. 27(2), 283-291.

SHIBA, S., HINO, S., HIRATA, Y., and SENO, T. (2000). Removal of heavy metal from soil and groundwater by in-situ electrokinetic remediation. Water Sci. Technol. 42(7-8), 335-343.

SPOSITO, G. (1984). The Surface Chemistry of Soils. New York: Oxford University Press.

SPOSITO, G. (1998). On points of zero charge. Environ. Sci. Technol. 32(19), 2815-2819. 
SUÈR, P., and ALLARD, B. (2003). Mercury transport and speciation during electrokinetic soil remediation. Water Air Soil Pollut. 143(1-4), 99-109.

SUÈR, P., and LIFBERGREN, T. (2003). Mercury-contaminated soil remediation by iodide and electroreclamation. ASCE J. Environ. Eng. 129(5), 441-446.

SUÈR, P., GITYE, K., and ALLARD, B. (2003). Speciation and transport of heavy metals and macroelements during electroremediation. Environ. Sci. Technol. 37(1), 177-181.

THEVANAYAGAM, S., and RISHINDRAN, T. (1998). Injection of nutrients and TEAs in clayey soils using electrokinetics. ASCE J. Geotech. Eng. 124(4), 330-338.

ULRICH, B., and SUMNER, M.E., Eds. (1991). Soil Acidity. Berlin: Springer-Verlag.

VADYUNINA, A.F. (1968). Meliorative effect of direct electric current on leaching solonchakous saloneta. In Trans. 9th Int. Congr. Soil Sci., Adelaide, Australia, Vol. 1, pp. 455-463.

VANE, L.M., and ZANG, G.M. (1997). Effect of aqueous phase properties on clay particle zeta potential and electro-osmotic permeability: Implications for electro-kinetic soil remediation processes. J. Hazard. Mater. 55(1-3), 1-22.

VELIZAROVA, E., RIBEIRO, A.B., and OTTOSEN, L.M. (2002). A comparative study on $\mathrm{Cu}, \mathrm{Cr}$ and As removal from CCA-treated wood waste by dialytic and electrodialytic processes. J. Hazard. Mater. 94(2), 147-160.

VENGRIS, T., BINKIENE, R., and SVEIKAUSKAITE, A. (2001). Electrokinetic remediation of lead-, zinc- and cadmium-contaminated soil. J. Chem. Technol. Biotech. 76(11), 1165-1170.

VEREDA-ALONSO, C., RODRIGUEZ-MAROTO, J.M., GARCIA-DELGADO, R.A., GÓMEZ-LAHOZ, C., and GARCÍA-HERRUZO, F. (2004) Two-dimensional model for soil electrokinetic remediation of heavy metals-Application to a copper spiked kaolin. Chemosphere 54(7), 895-903.

VIRKUTYTE, J., SILLANPÄ̈̈, M., and LATOSTENMAA, P. (2002). Electrokinetic soil remediation-Critical overview. Sci. Total Environ. 289(1-3), 97-121.

WADA, S.I., and UMEGAKI, Y. (2001). Major ion and electrical potential distribution in soil under electrokinetic remediation. Environ. Sci. Technol. 35(11), 2151-2155.

WENG, C.H., and YUAN, C. (2001). Removal of Cr(III) from clay soils by electrokinetics. Environ. Geochem. Health 23(3), 281-285.

WEST, L.J, and STEWART, D.I. (1995). "Effect of zeta potential on soil electrokinesis. In Y.B. Acar, and D.E. Daniel, Eds., Characterization, Containment, Remediation, and Performance in Environmental Geotechnics (Geotech.
Spec. Publ. No. 46) Vol. 2. New York: ASCE, pp. 1535-1549.

WONG, J.S.H., HICKS, R.E., and PROBSTEIN, R.F. (1997). EDTA-enhanced electroremediation of metal contaminated soils. J. Hazard. Mater. 55(1-3), 61-80.

YANG, G.C.C., and LIN, S.-L. (1998). Removal of lead from a silt loam by electrokinetic remediation. J. Hazard. Mater. 58(1-3), 285-299.

YANG, G.C.C., and LIU, C.Y. (2001). Remediation of TCE contaminated soils by in situ EK-Fenton process. J. Hazard. Mater. 85(3), 317-331.

YANG, G.C.C., and LONG, Y.-W. (1999). Removal and degradation of phenol in a saturated flow by in-situ electrokinetic remediation and Fenton-like process. J. Hazard. Mater. 69(3), 259-271.

YEUNG, A.T. (1990). Coupled flow equations for water, electricity, and ionic contaminants through clayey soils under hydraulic, electrical and chemical gradients. J. Non-Equilib. Thermodyn. 15(3), 247-267.

YEUNG, A.T. (1992). Diffuse double layer equations in SI units. ASCE J. Geotech. Eng. 118(12), 2000-2005.

YEUNG, A.T. (1994). Electrokinetic flow processes in porous media and their applications. In M.Y. Corapcioglu, Ed., Advances in Porous Media, vol. 2. Amsterdam: Elsevier, pp. 309-395.

YEUNG, A.T., and DATLA, S. (1995). Fundamental formulation of electro-kinetic extraction of contaminants from soil. Can. Geotech. J. 32(4), 569-583.

YEUNG, A.T., and HSU, C. (2005). Electrokinetic remediation of cadmium-contaminated clay. ASCE J. Environ. Eng. 131(2), 298-304.

YEUNG, A.T., HSU, C., and MENON, R.M. (1996). EDTAenhanced electrokinetic extraction of lead. ASCE J. Geotech. Eng. 122(8), 666-673.

YEUNG, A.T., and MITCHELL, J.K. (1993). Coupled fluid, electrical and chemical flows in soil. Géotechnique 43(1), 121-134.

YEUNG, A.T., SADEK, S.M., and MITCHELL, J.K. (1992). A new apparatus for the evaluation of electro-kinetic processes in hazardous waste management. ASTM Geotech. Test. J. 15(3), 207-216.

YEUNG, A.T., CHUNG, M., CORAPCIOGLU, M.Y., and STALLARD, W.M. (1997a). Impoundment liner repair by electrophoresis of clay. ASCE J. Environ. Eng. 123(10), 993-1001.

YEUNG, A.T., HSU, C., and MENON, R.M. (1997b). Physicochemical soil-contaminant interactions during electrokinetic extraction. J. Hazard. Mater. 55(1-3), 221-237. 
YEUNG, A.T., SCOTT, T.B., GOPINATH, S., MENON, R.M., and HSU, C. (1997c). Design, fabrication, and assembly of an apparatus for electrokinetic remediation studies. ASTM Geotech. Test. J. 20(2), 199-210.

YONG, R.N., and PHADUNGCHEWIT, Y. (1993). pH influence on selectivity and retention of heavy-metals in some clay soils. Can. Geotech. J. 30(5), 821-833.

YONG, R.N., WARKENTIN, B.P., PHADUNGCHEWIT, Y., and GALVEZ, R. (1990). Buffer capacity and lead retention in some clay materials. Water Air Soil Pollut. 53(1-2), 53-67.
YU, J.W., and NERETNIEKS, I. (1996). Modelling of transport and reaction processes in a porous medium in an electrical field. Chem. Eng. Sci. 51(19), 4355-4368.

YU, J.W., and NERETNIEKS, I. (1997). Theoretical evaluation of a technique for electrokinetic decontamination of soils. J. Contam. Hydrol. 26(1-4), 291-299.

ZAGURY, G.J., DARTIGUENAVE, Y., and SETIER, J.C. (1999). Ex situ electroreclamation of heavy metals contaminated sludge: pilot scale study. ASCE J. Environ. Eng. 125(10), 972-978. 